San Jose State University

SJSU ScholarWorks

Master's Theses

Master's Theses and Graduate Research

Fall 2020

\title{
Processing and Characterization of Ceria-Zirconia Containing Graphene Quantum Dots
}

Andrew Dina

San Jose State University

Follow this and additional works at: https://scholarworks.sjsu.edu/etd_theses

\section{Recommended Citation}

Dina, Andrew, "Processing and Characterization of Ceria-Zirconia Containing Graphene Quantum Dots" (2020). Master's Theses. 5169.

DOI: https://doi.org/10.31979/etd.pcg4-wzbz

https://scholarworks.sjsu.edu/etd_theses/5169

This Thesis is brought to you for free and open access by the Master's Theses and Graduate Research at SJSU ScholarWorks. It has been accepted for inclusion in Master's Theses by an authorized administrator of SJSU ScholarWorks. For more information, please contact scholarworks@sjsu.edu. 


\title{
PROCESSING AND CHARACTERIZATION OF CERIA-ZIRCONIA CONTAINING
} GRAPHENE QUANTUM DOTS

\author{
A Thesis \\ Presented to \\ The Faculty of the Department of Chemical and Materials Engineering \\ San José State University \\ In Partial Fulfillment \\ of the Requirements for the Degree \\ Master of Science
}

by

Andrew Dina

December 2020 
(C) 2020

Andrew Dina

ALL RIGHTS RESERVED 
The Designated Thesis Committee Approves the Thesis Titled

PROCESSING AND CHARACTERIZATION OF CERIA-ZIRCONIA CONTAINING GRAPHENE QUANTUM DOTS

\author{
by \\ Andrew Dina \\ APPROVED FOR THE DEPARTMENT OF CHEMICAL \\ AND MATERIALS ENGINEERING
}

SAN JOSÉ STATE UNIVERSITY

December 2020

Ozgur Keles, Ph.D.

Department of Chemical and Materials Engineering

David Parent, Ph.D. Department of Electrical Engineering

Amir Armani, Ph.D.

Department of Mechanical Engineering 


\title{
ABSTRACT \\ SODIUM BOROHYDRIDE SYNTHESIS AND CHARACTERIZATION OF CERIA- ZIRCONIA COPRECIPITATE WITH GRAPHENE QUANTUM DOTS
}

\author{
by Andrew Dina
}

Zirconia-based nanoparticles have been used in various applications, such as catalyst, filters, oxygen storage, and sensors. Among many synthesis methods to produce zirconia $\left(\mathrm{ZrO}_{2}\right)$ nanoparticles, aqueous sodium borohydride $\left(\mathrm{NaBH}_{4}\right)$ precipitation has shown to be simple and capable of large-scale production. In this work, the $\mathrm{NaBH}_{4}$ precipitation of $\mathrm{ZrO}_{2}$ was extended to include ceria $\left(\mathrm{CeO}_{2}\right)$ and graphene quantum dots (GQDs). The resulting nanocomposites were characterized by thermal, crystallographic, compositional, and electron microscopy analysis techniques. The presence of $\mathrm{CeO}_{2}$ lowered the amorphous to tetragonal phase transformation temperature by $\sim 40{ }^{\circ} \mathrm{C}$. The presence of GQDs did not affect the amorphous to tetragonal transformation temperature. In addition, cerium ions were inserted into the $\mathrm{ZrO}_{2}$ lattice with an increase to the interplanar spacing, seen by a slight shift in the diffraction peaks with no new peaks. Compositional analysis showed a stoichiometry between $13-14$ mol. \% ceria in the $\mathrm{ZrO}_{2}$ matrix with no elevated carbon concentration consistent with GQD doping levels. Agglomerated particles of several crystallites were observed and the presence of $\mathrm{CeO}_{2}$ increased the degree of agglomeration. The presence of GQDs was not conclusive, diffraction measurements were close to the theoretical value for the GQD basal plane, however, observation of the nanoparticles were not clear. More studies are needed to conclude the presence and functional interaction of GQDs and their role in nano-particle synthesis-structure relationships. 


\section{ACKNOWLEDGMENTS}

Even though this thesis is intended to be a singular effort, the success and completion comes from the gracious support of those around me. First and foremost, my greatest appreciation goes to my advisor, Dr. Ozgur Keles, for guiding me through the greatest experience of my educational journey. Extending past experimental work, Dr. Ozgur Keles has taught me how to be a better researcher, writer, and engineer in my pursuit of professional improvement. Secondly, I am sincerely grateful for the guidance, patience, and encouragement of my reading committee, Dr. Amir Armani and Dr. David Parent.

I am additionally thankful for the exposure of working with professionals in the industry. First, I would like to thank Dr. Jun Wang at Perkin Elmer for his guidance and expertise in thermal analysis. In addition, my great appreciation extends to my former colleagues at Nanolab Technologies, Dr. Jeff Gold and Dr. Zhou Yang, for their assistance with XPS and TEM analysis. Last but certainly not least, I would like to thank Yulia Grozman for her assistance and perseverance with TEM analysis.

Since the beginning of my educational journey, my family have been my greatest supporters in my corner. My deepest appreciation goes to my parents, Alan and Joy Dina, for helping me realize my potential and steer me in the right direction. Lastly, my sincere appreciation goes out to my sister, Nicole Dina, for being my role model to aspire to. 


\section{TABLE OF CONTENTS}

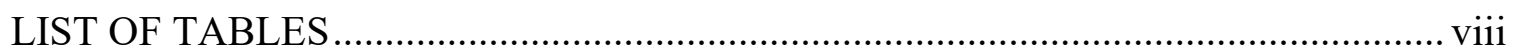

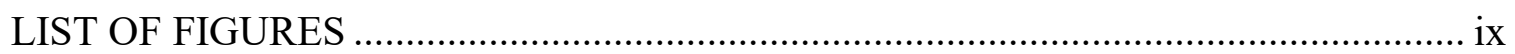

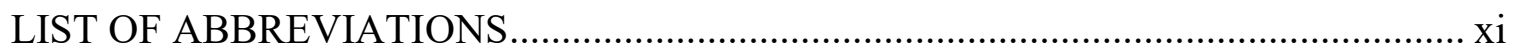

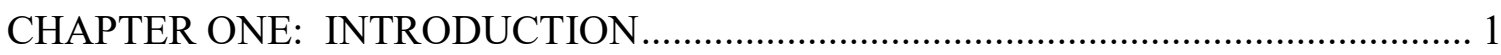

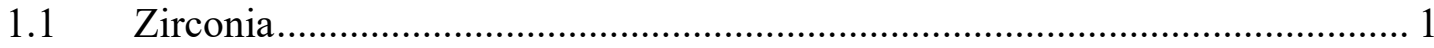

$1.2 \quad$ Partially Stabilized Zirconia …………………....................................... 3

$1.3 \quad$ Second Phase Dopants............................................................................... 4

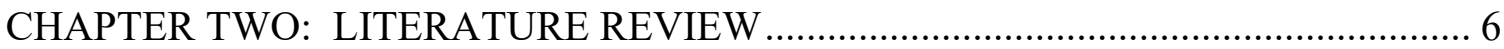

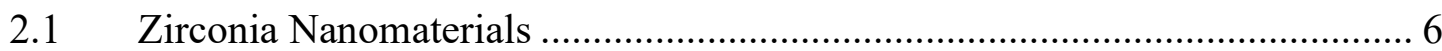

2.2 Ceria-Zirconia Nanomaterials …………………….................................. 20

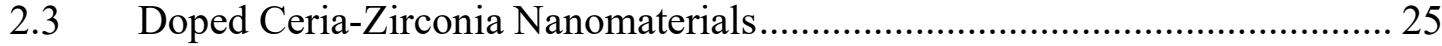

2.4 Carbon, Graphene and Quantum Dots......................................................... 27

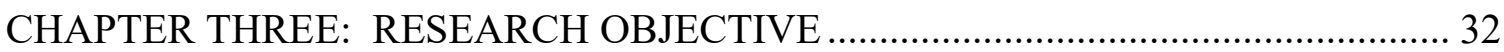

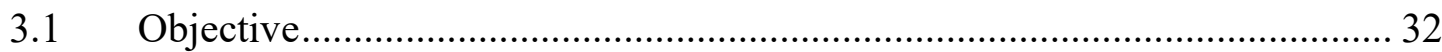

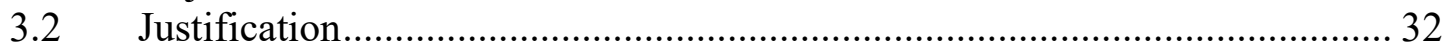

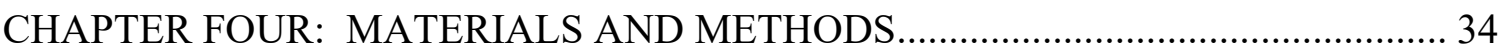

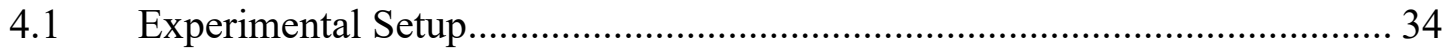

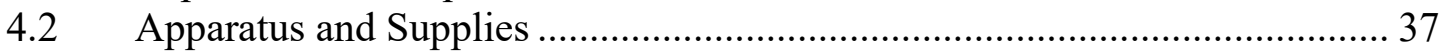

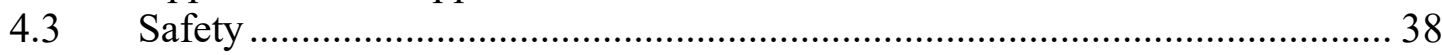

4.4 Analytical Instruments and Data Analysis .................................................. 40

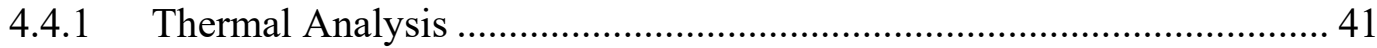

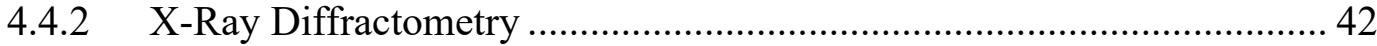

4.4.3 X-Ray Photoelectron Spectroscopy ....................................................... 42

4.4.4 Scanning Electron Microscopy ………………............................................ 43

4.4.5 Transmission Electron Microscopy ......................................................... 43

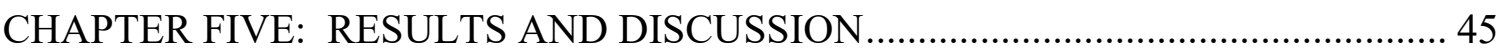

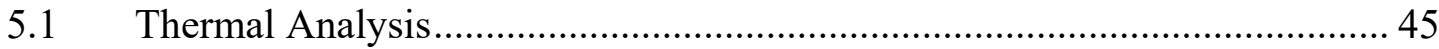

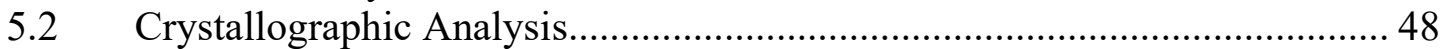

5.3 Compositional Analysis.............................................................................. 51

5.4 Morphology and Structural Analysis........................................................... 52 


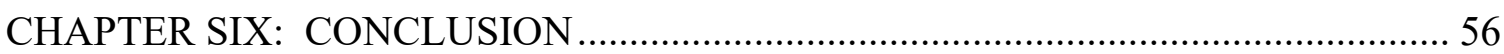

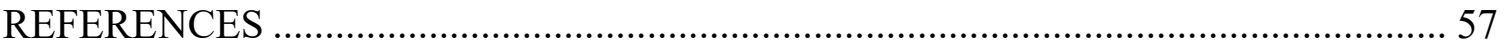




\section{LIST OF TABLES}

Table 1. Spray pyrolysis conditions and resulting crystallite size measured from $\mathrm{x}$-ray line broadening for two batches of $\mathrm{ZrO}_{2}$ powders [8]

Table 2. Referred samples for two batches of $\mathrm{ZrO}_{2}$ powders [8].

Table 3. Structure and degradation properties for $\mathrm{Ce}-\mathrm{ZrO}_{2}$ co-precipitation material systems [27].

Table 4. Sample matrix for GQD weight percent concentrations and calcination temperatures.

Table 5. Summary of hazard ratings, PPE and noteworthy information from the SDS for each chemical used in this study.

Table 6. Experimental matrix of analytical techniques used for each sample composition, GQD content, and thermal treatment.

Table 7. TGA weight loss steps and DSC events peaks tabulated for $\mathrm{ZrO}_{2}, \mathrm{Ce}-$ $\mathrm{ZrO}_{2}$, and $\mathrm{Ce}-\mathrm{ZrO}_{2}$ samples doped with either amine or carboxyl GQDs at both 0.1 and 0.5 wt. $\%$.

Table 8. Lattice parameter values tabulated for samples calcined at $700^{\circ} \mathrm{C}$. .50

Table 9. Compositional and $\mathrm{Ce}-\mathrm{ZrO}_{2}$ ratio results from XPS analysis. 51 


\section{LIST OF FIGURES}

Figure 1. XRD phase (a) and crystallite size (b) results with increasing calcine

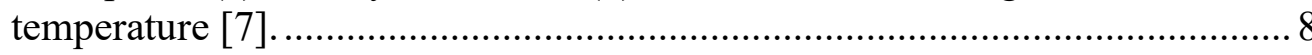

Figure 2. Specific surface (a) and excess energy (b) as a function of crystallite size for precipitated and calcined samples compared to theoretical values [7].

Figure 3. X-ray diffractograms of (a) I-6.9 and (b) II-13.2 versus crystallite size increase [8].

Figure 4. Raman spectra for $6.9 \mathrm{~nm}$ (a) and $18 \mathrm{~nm}$ (b) $\mathrm{ZrO} 2$ versus temperature [13].

Figure 5. TEM micrographs and histograms of $\mathrm{ZrO}_{2}$ nanostructures calcined at 500,600 , and $700^{\circ} \mathrm{C}[4]$.

Figure 6. SEM micrographs of the first synthesis method with rod-like particles (left), and the second synthesis method showing spherical shaped particles (right) [17].

Figure 7. DSC (solid line) and TGA (dashed line) curves of the zirconium acetate-complex [1].

Figure 8. XRD patterns of the zirconium acetate-complex for, (a) as synthesized, calcined at (b) 396, (c) 545, and (d) $710{ }^{\circ} \mathrm{C}$ [1].

Figure 9. DSC curves for as-synthesized $\mathrm{ZrO}_{2}$ powders (a) with and (b) without CTAB [18].

Figure 10. XRD results of $\mathrm{ZrO}_{2}$ powders annealed at $700{ }^{\circ} \mathrm{C}[8]$.

Figure 11. Degradation kinetics of 2-CEES for $\mathrm{Ce}-\mathrm{ZrO}_{2}$ co-precipitation material systems [27].

Figure 12. Process flow diagram to produce GQD doped Ce-ZrO2 nanocomposites.

Figure 13. Normalized DSC results for $\mathrm{ZrO} \neg 2$, $\mathrm{Ce}-\mathrm{ZrO} 2,0.5$ wt. \% amine GQD$\mathrm{Ce}-\mathrm{ZrO} 2$, and 0.5 wt. \% carboxyl GQD-Ce-ZrO2 samples.

Figure 14. TGA weight loss percent results for $\mathrm{ZrO} \neg 2, \mathrm{Ce}-\mathrm{ZrO} 2,0.5$ wt. \% amine GQD-Ce-ZrO2, and 0.5 wt. \% carboxyl GQD-Ce-ZrO2 samples. 
Figure 15. Onset of crystallinity with increased annealing temperature of $\mathrm{ZrO}_{2}$ by XRD.

Figure 16. XRD intensity peaks for $\mathrm{ZrO} \neg 2, \mathrm{Ce}-\mathrm{ZrO} 2, \mathrm{Ce}-\mathrm{ZrO} 2$ with amine GQDs or carboxyl GQDs, containing either 0.1 or 0.5 wt. \% GQDs, all annealed at $700{ }^{\circ} \mathrm{C}$

Figure 17. HAADF TEM and EDS mapping images of separate Ce-based agglomerated particles for 0.5 wt. \% amine GQD-Ce-ZrO2 sample calcined at $400{ }^{\circ} \mathrm{C}$.

Figure 18. High Resolution SEM (HRSEM) micrographs showing particle morphology of (a) $\mathrm{ZrO}_{2}$, (b) $\mathrm{CeZrO}_{2}$, and $\mathrm{CeZrO}_{2}$ with (c) 0.5 wt.\% amine GQDs and (d) 0.5 wt.\% carboxyl GQDs.

Figure 19. HRTEM micrographs showing diffraction patterns and lattice measurements for (a) $\mathrm{ZrO}_{2}$, (b) $\mathrm{Ce}-\mathrm{ZrO}_{2}$, (c) 0.1 wt. \% amine GQD-Ce$\mathrm{ZrO}_{2}$ (d) 0.5 wt.\% amine GQD-Ce- $\mathrm{ZrO}_{2}$.

Figure 20. HRTEM micrographs of the (a) 0.5 wt. $\%$ amine GQD-Ce- $\mathrm{ZrO}_{2}$ sample unannealed and of the (b) 0.5 wt. \% amine GQD-Ce- $\mathrm{ZrO}_{2}$ annealed at $700{ }^{\circ} \mathrm{C}$. 


\section{LIST OF ABBREVIATIONS}

2-CEES - 2-chloroethyle ethyl sulfide

BET - Brunauer-Emmett-Teller

BJH - Barrett-Joyner-Halenda

$\mathrm{CeCl}_{3} \cdot 7 \mathrm{H}_{2} \mathrm{O}$ - cerium chloride heptahydrate

$\mathrm{CeO}_{2}-$ ceria

$\mathrm{Ce}-\mathrm{ZrO} \mathrm{r}_{2}$ - ceria-zirconia

$\mathrm{CTAB}$ - cetyltrimethylammonium bromide

DI - deionized

DSC - Differential Scanning Calorimetry

EDS - Energy Dispersive Spectroscopy

$\mathrm{Eu}$ - europium

GQDs - graphene quantum dots

GQD-Ce- $\mathrm{ZrO}_{2}$ - ceria-stabilized zirconia containing GQDs

HRSEM - High Resolution SEM

HRTEM - High Resolution Transmission Electron Microscope

IPA - isopropyl alcohol

$\mathrm{La}_{2} \mathrm{O}_{3}$ - lanthana

$\mathrm{NaBH}_{4}$ - sodium borohydride

$\mathrm{m}-\mathrm{ZrO}_{2}$ - monoclinic zirconia

$\mathrm{OH}^{-}$- hydroxyl

OSC - oxygen storage capacity

PPE - personal protective equipment

PSZ - partially stabilized zirconia

$\mathrm{Pt}$ - platinum

SDS - safety data sheets

SEM - Scanning Electron Microscopy

$\mathrm{Sr}$ - strontium

TEM - Transmission Electron Microscopy

TGA - Thermogravimetric Analysis

$\mathrm{TiO}_{2}-$ titania

TPR - Temperature Program Reduction

TZP - tetragonal zirconia polycrystals

$\mathrm{t}-\mathrm{ZrO}_{2}$ - tetragonal zirconia

XPS - X-ray Photoelectron Spectroscopy

XRD - X-ray Diffractometry

$\mathrm{ZrO}_{2}$ - zirconia

$\mathrm{Zr}(\mathrm{OH})_{4}$ - zirconium hydroxide

$\mathrm{ZrOCl}_{2} \cdot 8 \mathrm{H}_{2} \mathrm{O}$ - zirconium oxychloride octahydrate 


\section{CHAPTER ONE}

\section{INTRODUCTION}

Zirconium dioxide $\left(\mathrm{ZrO}_{2}\right)$-based ceramics have been a popular material of choice for a variety of industries due to outstanding material characteristics. High mechanical strength, toughness, wear and corrosion resistance make $\mathrm{ZrO}_{2}$-based ceramics optimal in structural and bearing applications [1]. Due to its high thermal resistance to shock and low thermal conductivity, zirconias are a good choice for the refractory and coatings industries [1]. In addition, $\mathrm{ZrO}_{2}$-based ceramics have become the dominant ceramic of choice in the biomedical industry for applications like medical and dental implants due to superior biocompatibility and mechanical properties [2]. Also, in the presence of oxygen, $\mathrm{ZrO}_{2}$-based ceramics have been very stable making them a good choice in oxygen rich systems such as fuel cells and oxygen sensors for the fuel and automotive industries [3]. In addition, zirconia has been used in optical applications such as photonics, interferometry filters, and laser mirror coatings due to its hardness, optical transparency and refractive index [4]. $\mathrm{ZrO}_{2}$-based ceramic systems usefulness across a large number of applications can be attributed to the dominant material properties within its different phases and unique properties.

\subsection{Zirconia}

$\mathrm{ZrO}_{2}$ is a white crystalline oxide that naturally occurs in the form of mineral baddeleyite [5]. As a polymorph, it holds three crystalline phases; monoclinic stable below $1170{ }^{\circ} \mathrm{C}$, tetragonal stable between $1170-2370{ }^{\circ} \mathrm{C}$, and cubic stable above $2370{ }^{\circ} \mathrm{C}$ [2]. Each phase holds different dominant material properties best tailored for a variety of 
applications. In order to utilize high temperature phases at lower temperature applications, these phases must be in a stabilized state, or metastable state [6]. There have been a variety of mechanisms proposed to explain these metastable states: either thermodynamic factors influenced by particle size, surface area, and surface tension $[7,8]$, or kinetic factors such as impurities, vacancies, and lattice defects [9-12]. For example, tetragonal zirconia $\left(\mathrm{t}-\mathrm{ZrO}_{2}\right)$ particles below a critical size of $\sim 30 \mathrm{~nm}$ stabilize at room temperature, above which the surface free energy drives transformation to the monoclinic zirconia $\left(\mathrm{m}-\mathrm{ZrO}_{2}\right)$ phase [7].

How we synthesize $\mathrm{ZrO}_{2}$ plays an important role in stabilizing a phase and has been extensively investigated [1,4,13-15]. Different synthesis techniques, such as sol-gel, spray pyrolysis, calcination, and precipitation, have been reported to affect crystal phases and morphology $[4,8,16,17]$. For example, a metathesis reaction yields either rod-like tetragonal or spherical shaped cubic $\mathrm{ZrO}_{2}$ particles by merely changing the method of mixing the precursors prior to thermal treatment [17]. Among these synthesis techniques, precipitation methods are simple and suitable for large scale production $[1,18]$. One of these precipitation synthesis techniques uses sodium borohydride $\left(\mathrm{NaBH}_{4}\right)$ to reduce zirconium oxychloride octahydrate $\left(\mathrm{ZrOCl}_{2} \cdot 8 \mathrm{H}_{2} \mathrm{O}\right)$ to zirconium hydroxide $\left(\mathrm{Zr}(\mathrm{OH})_{4}\right)$ [18-20]. This reduction reaction produces amorphous $\mathrm{ZrO}_{2}$ with heat-treatment below $400{ }^{\circ} \mathrm{C}$ [18-20]. The $\mathrm{NaBH}_{4}$ synthesis occurs at room temperature [19]; hence, offers flexibility of using surfactants, dopants, and second phases to tailor final $\mathrm{ZrO}_{2}$ structure and composition for particular applications [18-20]. 


\subsection{Partially Stabilized Zirconia}

Another method for controlling phase stabilization of $\mathrm{ZrO}_{2}$ has been the use of surfactants and dopants. For example, the addition of cetyltrimethylammonium bromide (CTAB) surfactant produced flake-like $\mathrm{t}-\mathrm{ZrO}_{2}$ particles [18]. There is a two-pronged challenge with using surfactants. First, the surfactant can have unintended reactions during either synthesis or application. Second, surfactants are not the best method for addressing the large volume change inherent with $\mathrm{ZrO}_{2}$ phase changes. In both manufacturing and applications, $\mathrm{ZrO}_{2}$ 's high fracture toughness and hardness is due to transformation toughening, a reversable martensitic tetragonal-to-monoclinic phase change when subjected to either stress or heat [21]. There is a 4-5\% volume change during this transformation that can cause inter-granular fracture [21]. However, dopants have been found to both stabilize high temperature phases at lower temperatures while allowing the material to withstand the large volume change during phase transformation $[9,21]$.

Coined partially stabilized zirconia (PSZ), dopants like calcia, yttria, magnesia, and rare earth metals have shown to stabilize $\mathrm{ZrO}_{2}$ while improving a variety of material properties [22-24]. Among one of the first, small amounts of yttria doping has been used to stabilize tetragonal zirconia polycrystals (TZP) while increasing mechanical properties like strength, hardness, and toughness [25]. Ceria $\left(\mathrm{CeO}_{2}\right)$ has been one of the most promising and fruitful stabilizing dopants for its ability to enhance $\mathrm{ZrO}_{2}$ unique transformation toughening effect [25]. It was reported the fracture toughness almost doubled from 4 to $7 \mathrm{MPa} \cdot \mathrm{m}^{1 / 2}$ due to transformation behavior when TZP was stabilized 
with $18 \mathrm{~mol} \% \mathrm{CeO}_{2}$ [26]. Since then, $\mathrm{CeO}_{2}$-stabilized zirconia $\left(\mathrm{Ce}-\mathrm{ZrO}_{2}\right)$ based systems have received a large amount of research to expand and optimize material properties for a variety of applications [27-31].

\subsection{Second Phase Dopants}

Secondary phase dopants can also tailor material properties for particular applications of $\mathrm{ZrO}_{2}$-based nanocomposites. Specifically, carbon-based second phases have been reported to affect various properties like optical, electrical, catalytic, and mechanical [3235]. For example, the photocatalytic efficiency of $\mathrm{ZrO}_{2}$ was almost doubled when doped with 8.3 wt. \% graphene [32]. Additionally, doping yttria- $\mathrm{ZrO}_{2}$ with greater than 2.2 vol. $\%$ of graphene nanoplatelets decreased the composite hardness, suppressed the formation of tetragonal phase, and increased the electrical conductivity [33].

Unlike larger carbon-based secondary phases, graphene quantum dots (GQDs) are a relatively new material that are smaller than $10 \mathrm{~nm}$ in diameter with a single to a few layers of graphene [36,37]. GQDs are used for bioimaging, biomarking, drug delivery, fluorescent sensing, and photovoltaics due to their biocompatibility, photoluminescence, and electronic properties [38-44]. By changing the size, shape, and functional groups of GQDs, photoluminescence behavior has been adjusted to cover the ultraviolet to near infrared emission spectrum range [38,39].

The use of GQDs as a secondary phase dopant has the potential of optimizing particular material properties tailored for engineering applications. For example, GQDs were reported to increase toughness, elastic modulus, and tensile strength of epoxy with the addition of 1.0 to $2.5 \mathrm{wt}$ \% of GQDs [45]. GQDs were also reported to increase the 
electrical conductivity and hardness of cellulose acetate films [46]. With respect to metal-oxide ceramics, an increase in visible light absorption and photocatalytic activity in anatase titania $\left(\mathrm{TiO}_{2}\right)$ with GQDs was reported [47]. If GQDs were added to PSZ, there could potentially be an increase in toughness that perhaps would reduce the intergranular fracture inherent during transformation toughening. This speculative result could in turn mean higher degree of shape memory deformation with larger elongation before fracture. The processability of PSZ ceramics containing GQDs are unclear in the literature and warrant investigation.

In this work, previously synthesized $\mathrm{Ce}-\mathrm{ZrO}_{2}$ nanoparticles doped with GQDs were characterized. $\mathrm{NaBH}_{4}$ precipitation derived $\mathrm{ZrO}_{2}, \mathrm{Ce}-\mathrm{ZrO}_{2}$ and Ce-stabilized $\mathrm{ZrO}_{2}$ containing GQDs (GQD-Ce-ZrO 2 ) were analyzed. In addition, two different GQDs with amine and carboxyl functional groups were used to observe the effects functional groups had on morphology and structure of $\mathrm{ZrO}_{2}$. Differential scanning calorimetry (DSC) and thermogravimetric analysis (TGA) were used to observe the phase behavior, while X-ray diffractometry (XRD) was used to identify the associated crystalline phases. X-ray photoelectron spectroscopy (XPS), and transmission electron microscopy (TEM), coupled with energy dispersion spectroscopy (EDS) were used to characterize the composition, size, structure, and bonding states of the nanoparticles. And lastly, scanning electron microscopy (SEM) was used to observe the morphology of the resulting $\mathrm{ZrO}_{2}$-based ceramic composites. 


\section{CHAPTER TWO}

\section{LITERATURE REVIEW}

\subsection{Zirconia Nanomaterials}

Since the first reporting of metastable $\mathrm{t}-\mathrm{ZrO}_{2}$ in 1929 [48], much research has been done to understand how metastable phases are obtained. Garvie was among the first to use experimental work and thermodynamics to explain the relationship between crystallite size and low temperature metastable $\mathrm{t}-\mathrm{ZrO}_{2}$ phase [7]. With two synthesis methods, precipitation of zirconyl nitrate and sodium hydroxide to produce a hydrous oxide [7], and calcination by thermal treatment of the anhydrous nitrate at $400{ }^{\circ} \mathrm{C}$ for 48 hours, Garvie produced metastable $\mathrm{t}-\mathrm{ZrO}_{2}$ [7]. To study the phase dependency, both samples were heated in air at various temperatures up to $1000^{\circ} \mathrm{C}$ for 24 hours [7]. XRD analysis showed a transition from tetragonal to monoclinic as thermal treatment increased, as shown in Figure 1a [7]. Precipitation held the tetragonal phase at higher annealing temperatures than calcination, showing signs of monoclinic transformation at approximately $700^{\circ} \mathrm{C}$, and complete monoclinic phase at approximately $775^{\circ} \mathrm{C}$ [7]. The calcined oxide started developing monoclinic phase at approximately $525^{\circ} \mathrm{C}$ and complete monoclinic phase at approximately $800{ }^{\circ} \mathrm{C}$ [7]. Figure $1 \mathrm{~b}$ is a graphical representation of the average $\mathrm{t}-\mathrm{ZrO}_{2}$ crystallite size with respect to temperature [7]. As the heating temperature increased, the average crystallite size for both samples converged near $30 \mathrm{~nm}$, above which both samples transformed completely to monoclinic phase [7]. Brunauer-Emmett-Teller (BET) was used to obtain the specific surface area for each sample at various heating temperatures in order to thermodynamically correlate crystallite 
size and phases [7]. As the crystallite size increased, the specific surface area and excess energy decreased, both near a minimum of about $30 \mathrm{~nm}$, Figures $2 \mathrm{a}$ and $2 \mathrm{~b}$, respectively [7]. These results suggested there was an equilibrium between the tetragonal and monoclinic phases at a crystallite size of about $30 \mathrm{~nm}$ [7]. Equation 1 is the relationship in terms of molar free energy $(G)$, surface energy $(\gamma)$, and molar surface (A), where subscripts $t$ and $m$ denote tetragonal and monoclinic, respectively [7]. This study suggests two different synthesis methods can stabilize $\mathrm{t}-\mathrm{ZrO}_{2}$ at room temperature when the average crystallite size is less than $30 \mathrm{~nm}$ with appreciable surface area and excess energy [7].

$$
G_{m}+\gamma_{m} A_{m}=G_{t}+\gamma_{t} A_{t}
$$

Equation 1 

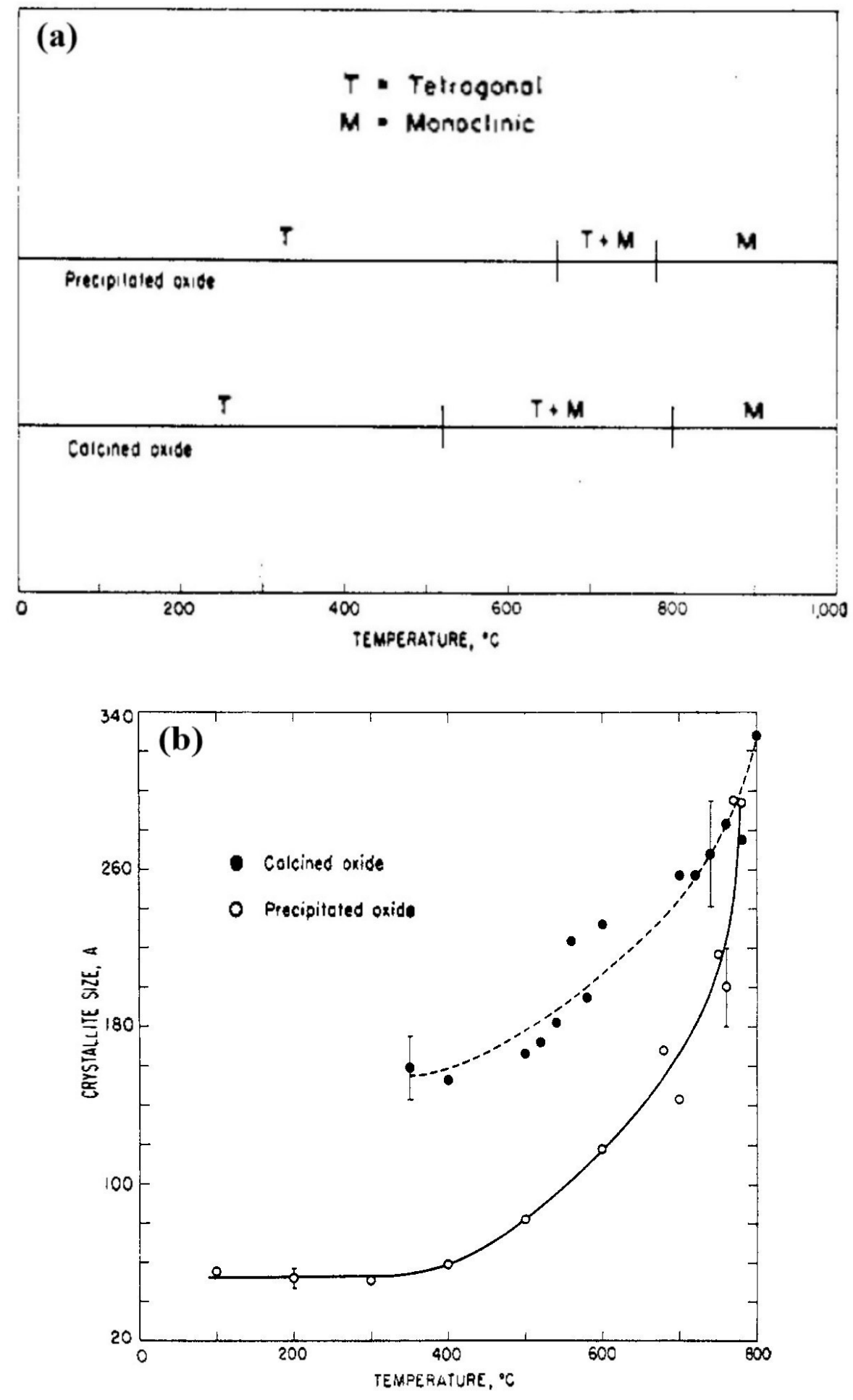

Figure 1. XRD phase (a) and crystallite size (b) results with increasing calcine temperature [7]. 

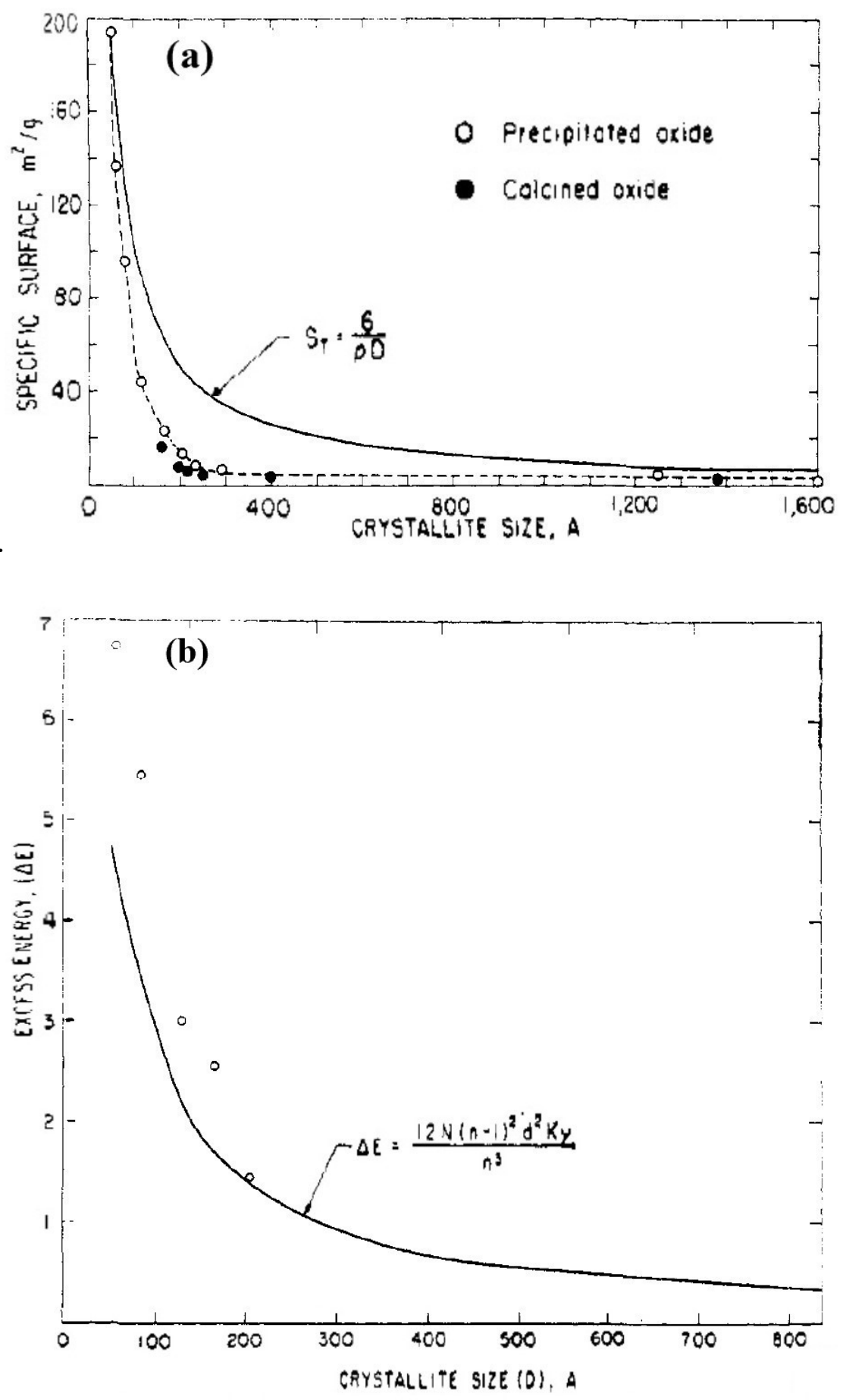

Figure 2. Specific surface (a) and excess energy (b) as a function of crystallite size for precipitated and calcined samples compared to theoretical values [7]. 
The transformation behavior of metastable $\mathrm{ZrO}_{2}$ is influenced by what synthesis method is used. In another study, Djurado et. al. used a spray-pyrolysis method with different post synthesis calcination temperatures to show a relationship between crystallite size and metastable tetragonal-monoclinic phase transformations [8]. An ultrasonic atomizer with a mist generator operating at $850 \mathrm{kHz}$ and $1.7 \mathrm{MHz}$ frequencies was used to produce two samples with starting average crystallite sizes of 6.9 and 13.2 $\mathrm{nm}$, respectively [8]. Table 1 is a tabulation of the synthesis conditions used to produce the two batches [8]. The samples were then annealed in platinum (Pt) crucibles for temperatures ranging from $600-1400{ }^{\circ} \mathrm{C}$ at a heating rate of $5{ }^{\circ} \mathrm{C} \min ^{-1}$ for times ranging from 15 minutes to 2 hours [8]. Table 2 shows the annealing temperatures and times for the two sample types with their resulting crystallite sizes [8]. Utilizing XRD and Raman spectroscopy, it was found that the critical size effect for a particular phase varied with preparation, moisture concentration, and percent of phases present prior to annealing [8]. The $6.9 \mathrm{~nm}$ starting sample had approximately $5 \%$ monoclinic phase whereas the 13.2 nm starting sample was less than $1 \%$, if any due to the resolution of the technique [8]. The presence of monoclinic phase prior to annealing yielded a faster transformation to monoclinic phase at lower temperatures, even at smaller crystallite sizes [8]. Figure 3 is the XRD results for the various samples in this study and shows this synthesis method produces nanoparticles of both tetragonal and monoclinic phases with only a difference in the synthesis parameters [8]. In addition, either the smaller crystallite size or the presence of monoclinic phase caused a gradual transformation with increasing annealing temperatures, whereas the larger starting crystallite size showed a sudden tetragonal to 
monoclinic phase transformation [8]. Unfortunately, a surface area study was not conducted, as it may have offered an interesting explanation to the varying phase transformation behaviors between the different starting crystallite size samples, or at the least showed support for or against Garvie's thermodynamic explanation.

Table 1. Spray pyrolysis conditions and resulting crystallite size measured from x-ray line broadening for two batches of $\mathrm{ZrO}_{2}$ powders [8].

\begin{tabular}{cccccc}
\hline Batch No. & $\begin{array}{c}\text { Concentration } \\
\left(\mathrm{mol} \mathrm{L}^{-1}\right)\end{array}$ & $\begin{array}{c}\text { Frequency } \\
(\mathrm{kHz})\end{array}$ & $\begin{array}{c}\text { Flow rate } \\
\left(\mathrm{L} \mathrm{min}^{-1}\right)\end{array}$ & $\begin{array}{c}\text { Temperature } \\
\left({ }^{\circ} \mathrm{C}\right)\end{array}$ & $\begin{array}{c}\text { Crystallite } \\
\text { size }(\mathrm{nm})\end{array}$ \\
\hline I & $2.5 \times 10^{-2}$ & $1.7 \times 10^{3}$ & 6 & 600 & 6.9 \\
II & $2.5 \times 10^{-2}$ & 850 & 3 & 900 & 13.2 \\
\hline
\end{tabular}

Table 2. Referred samples for two batches of $\mathrm{ZrO}_{2}$ powders [8].

\begin{tabular}{lcc}
\hline Annealing conditions in air & $\begin{array}{c}\text { Batch I, Crystallite size } \\
(\mathrm{nm})\end{array}$ & $\begin{array}{c}\text { Batch II, Crystallite size } \\
(\mathrm{nm})\end{array}$ \\
\hline No annealing & 6.9 & 13.2 \\
$600^{\circ} \mathrm{C}, 15 \mathrm{~min}$ & 8.3 & 13.8 \\
$600^{\circ} \mathrm{C}, 2 \mathrm{~h}$ & 8.9 & 13.3 \\
$800{ }^{\circ} \mathrm{C}, 2 \mathrm{~h}$ & 20.3 & 18.0 \\
$900{ }^{\circ} \mathrm{C}, 15 \mathrm{~min}$ & 21.0 & 21.8 \\
$950{ }^{\circ} \mathrm{C}, 1 \mathrm{~h}$ & 30.1 & 22.0 \\
$1000^{\circ} \mathrm{C}, 1 \mathrm{~h}$ & 36.3 & 25.5 \\
$1400{ }^{\circ} \mathrm{C}, 2 \mathrm{~h}$ & 65.2 & 85.8 \\
\hline
\end{tabular}



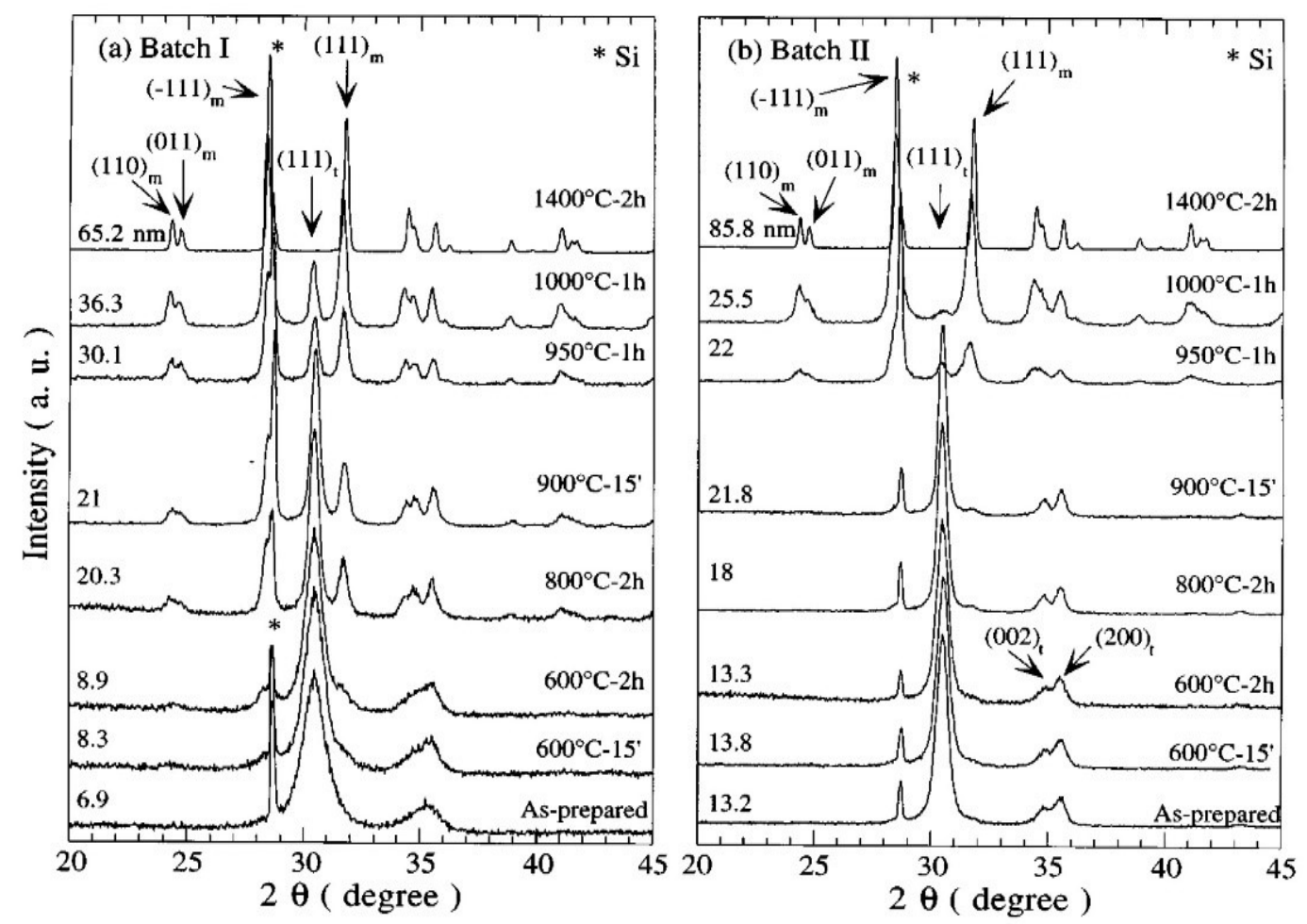

Figure 3. X-ray diffractograms of (a) I-6.9 and (b) II-13.2 versus crystallite size increase [8].

Like Djurado's research showed, the starting phase composition makes a difference even at sub room temperature conditions. Bouvier et. al. continued the study of Djurado by investigating sub room temperature phase stability and any correlation with crystallite size for $\mathrm{ZrO}_{2}$ samples produced by the same spray pyrolysis synthesis method [13]. Three samples with different average crystallite sizes, $6.9,13$, and $18 \mathrm{~nm}$, were analyzed using Raman and neutron scatter spectroscopy techniques through a temperature range of $296 \mathrm{~K}$ to $96 \mathrm{~K}$ [13]. Figure 4 is the Raman spectra for the 6.9 and $18 \mathrm{~nm}$ samples [13]. The broadness of the peaks for the $6.9 \mathrm{~nm}$ sample indicated the presence of an initial $5 \%$ monoclinic phase and the broadening of the shoulder around $350 \mathrm{~cm}^{-1}$ indicated an increased monoclinic concentration with decreasing temperature [13]. It was also noted 
that upon returning to room temperature, $6.9 \mathrm{~nm}$ sample returned back to its initial state suggesting a reversible structural evolution with a crystallite size at least as small as 6.9 $\mathrm{nm}$ [13]. The 13 and $18 \mathrm{~nm}$ sample spectra were virtually identical and showed no significant change through the temperature range indicating $\mathrm{t}-\mathrm{ZrO}_{2}$ is stable at low temperatures with a crystallite size as low as $13 \mathrm{~nm}$ [13].
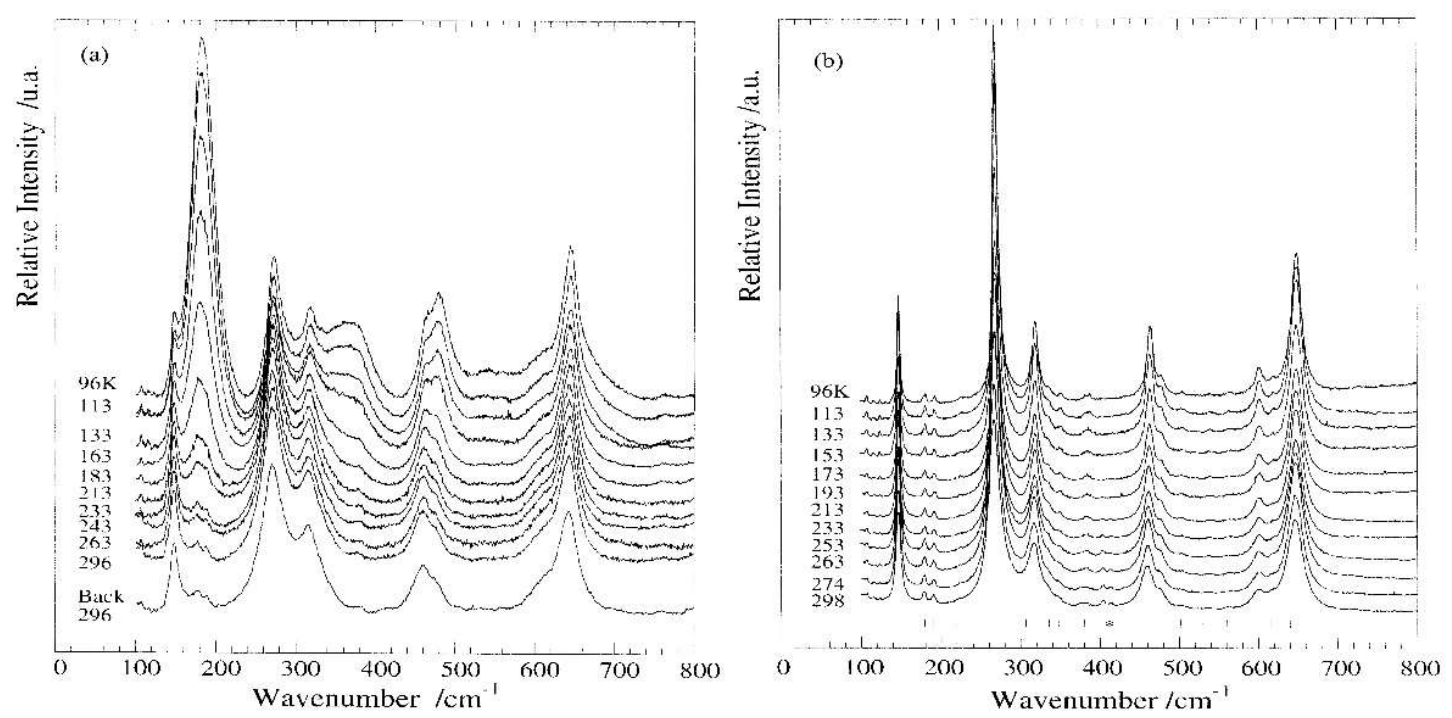

Figure 4. Raman spectra for $6.9 \mathrm{~nm}$ (a) and $18 \mathrm{~nm}$ (b) $\mathrm{ZrO} 2$ versus temperature [13].

In another study, Kumar and coworkers researched a sol-gel synthesis method to produce $\mathrm{ZrO}_{2}$ nanostructures at different calcination temperatures that also resulted with a mixture of phases [4]. By varying the calcination temperature, they were able to show that not only can different phases be achieved but different morphologies as well [4]. $\mathrm{ZrOCl}_{2} \cdot 8 \mathrm{H}_{2} \mathrm{O}$ was dissolved in distilled water and an ammonia solution was added dropwise to precipitate a $\mathrm{Zr}(\mathrm{OH})_{4}$ solution [4]. Calcination of the solution for three hours finalized the synthesis process of $\mathrm{ZrO}_{2}$ nanoparticles [4]. Calcination at $500{ }^{\circ} \mathrm{C}$ yielded pure tetragonal phase with a crystallite size of about $8 \mathrm{~nm}$ and a spherical morphology 
[4]. Calcination at $600{ }^{\circ} \mathrm{C}$ yielded a mixture of $73 \%$ tetragonal and $27 \%$ monoclinic phases with an average crystallite size of $17 \mathrm{~nm}$ and a spherical morphology [4]. The sample calcined at $700{ }^{\circ} \mathrm{C}$ also had a combination of $36 \%$ tetragonal and $64 \%$ monoclinic phases but had a reduced crystallite size of $10 \mathrm{~nm}$ with a rod like morphology [4]. Figure 5 shows TEM micrographs and histograms of the morphology and size of the three samples [4].
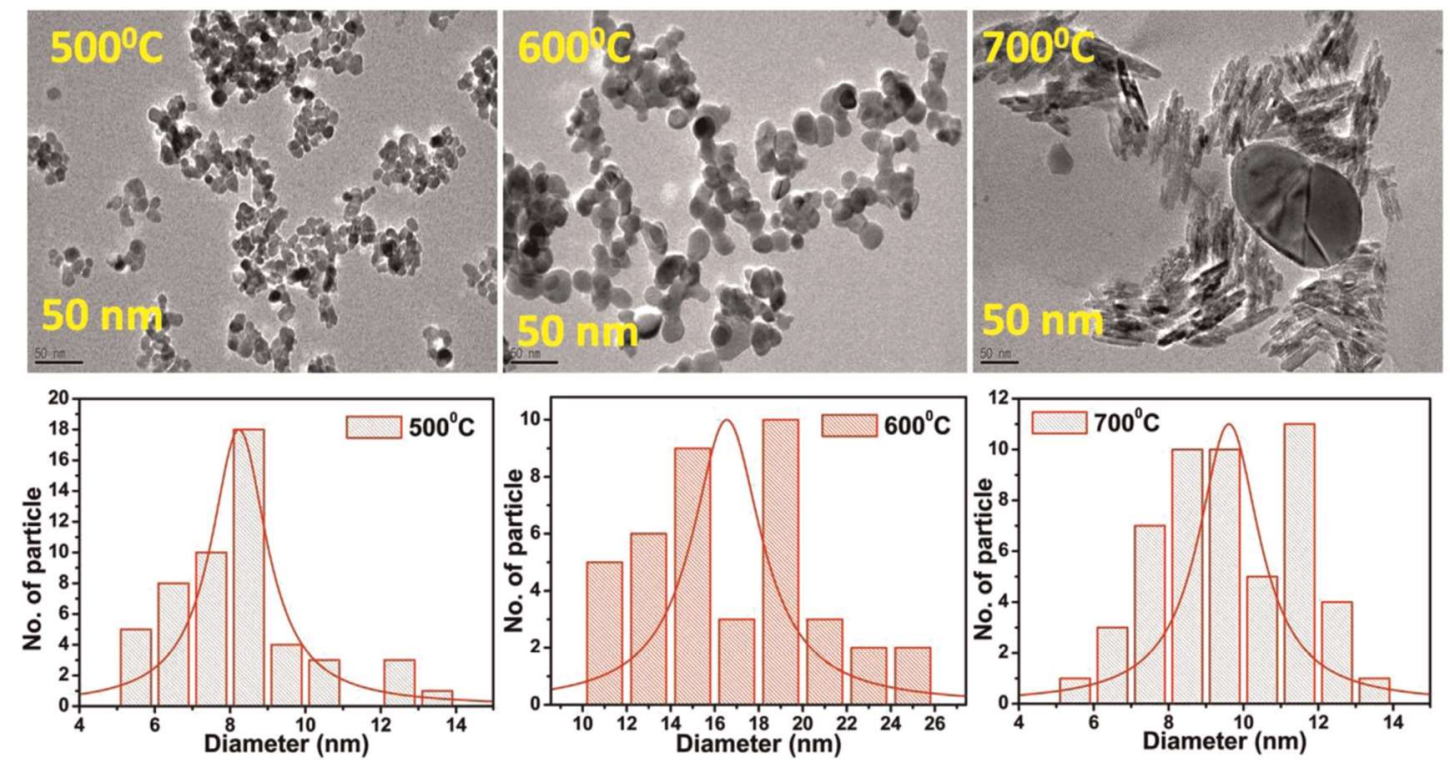

Figure 5. TEM micrographs and histograms of $\mathrm{ZrO}_{2}$ nanostructures calcined at 500, 600, and $700^{\circ} \mathrm{C}[4]$.

Contrary to the crystallite size effect observed in the research above, Grover et. al. showed that stabilized $\mathrm{t}-\mathrm{ZrO}_{2}$ particles can be achieved with different morphologies and crystallite sizes in the micron range [17]. Grover and coworkers used two synthesis methods to produce $\mathrm{ZrO}_{2}$ particles with different morphologies [17]. The first method was simply to sprinkle zirconium oxychloride $\left(\mathrm{ZrOCl}_{2}\right)$ powder over sodium hydroxide $(\mathrm{NaOH})$ pellets and heat the mixture at $400{ }^{\circ} \mathrm{C}$ for 4 hours [17]. The resulting material 
was noted to self-separate into sodium chloride and $\mathrm{ZrO}_{2}$ where XRD and SEM analysis showed a $\mathrm{t}-\mathrm{ZrO}_{2}$ phase with rod-like shaped particles having diameters of about 100 microns [17]. The second synthesis method ground the two precursors together, rinsed and dried them at $120{ }^{\circ} \mathrm{C}$ resulting in spherical shaped t-ZrO2 particles of sizes ranging between 1-5 microns [17]. Figure 6 is SEM micrographs of the resulting morphologies of the two different synthesis methods of $\mathrm{t}-\mathrm{ZrO}_{2}[17]$.

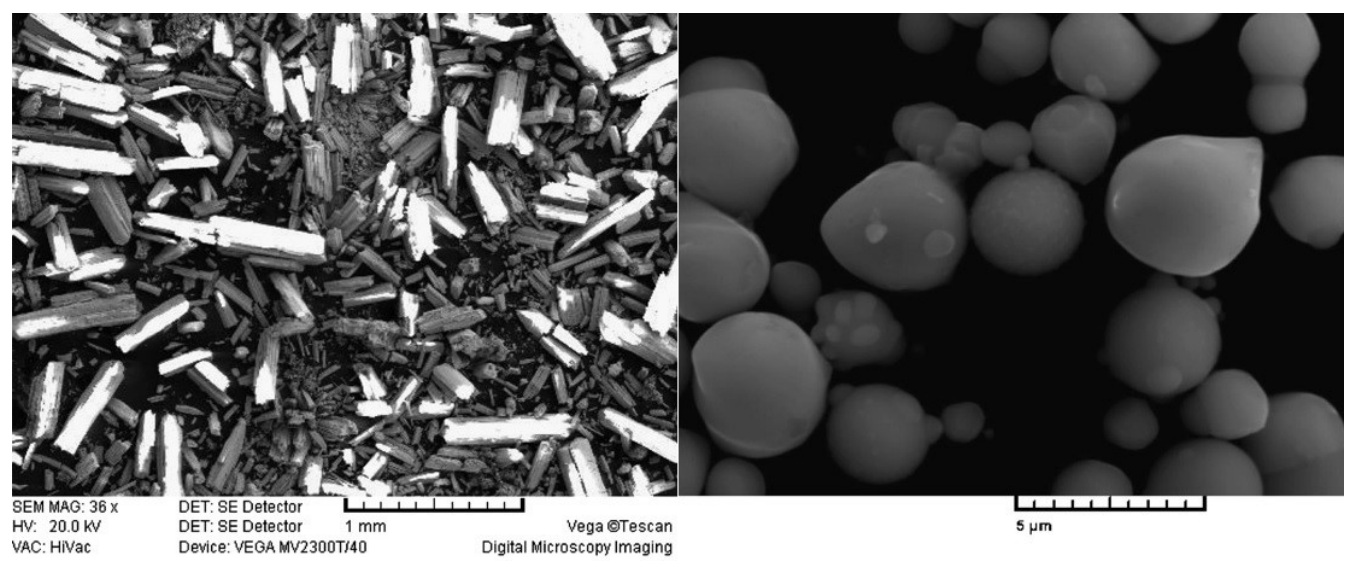

Figure 6. SEM micrographs of the first synthesis method with rod-like particles (left), and the second synthesis method showing spherical shaped particles (right) [17].

Of all the synthesis methods, precipitation has been shown to simplify the process along with reduce the time and energy needed for production of $\mathrm{ZrO}_{2}$ nanoparticles [1]. Guo et. al. developed a precipitation process to produce zirconium oxy-hydroxy-acetate from readily available zirconium oxychloride and acetic acid [1]. By simply mixing the two with constant stirring and $\mathrm{pH}$ monitoring, zirconium oxy-hydroxy-acetate was produced [1]. After aging for two days, washing with DI water and drying at $70{ }^{\circ} \mathrm{C}$ for 56 hours, the solution was ready to anneal at various temperatures to observe the ability to form $\mathrm{ZrO}_{2}$ nanoparticles [1]. DSC, TGA, and XRD were used to identify the thermal 
events that occurred over the temperature range of room temperature to $800{ }^{\circ} \mathrm{C}[1]$. Figures 7 and 8 are the DSC/TGA and XRD results, respectively [1]. XRD analysis for the as prepared sample was found to be amorphous with absence of any diffraction peaks [1]. TGA weight loss observed from room temperature up to about $396^{\circ} \mathrm{C}$ was primarily attributed to dehydration of the sample where the first thermal event at $119{ }^{\circ} \mathrm{C}$ was from desorption of physically absorbed water [1]. The second thermal event at $396{ }^{\circ} \mathrm{C}$ was attributed to decomposition of the acetate complex and XRD results show formation of some $\mathrm{t}-\mathrm{ZrO}_{2}$ with an average crystallite size of $24.3 \mathrm{~nm}$ [1]. Further heating to 545 and $710{ }^{\circ} \mathrm{C}$ revealed increased tetragonal crystallinity with an increasing presence of the monoclinic crystalline phase and increased crystallite sizes of 30.4 and $113.1 \mathrm{~nm}$, respectively [1]. This precipitation process suggests a simple synthesis method that can produce $\mathrm{ZrO}_{2}$ nanoparticles but does not exhibit pure phase crystallinity.

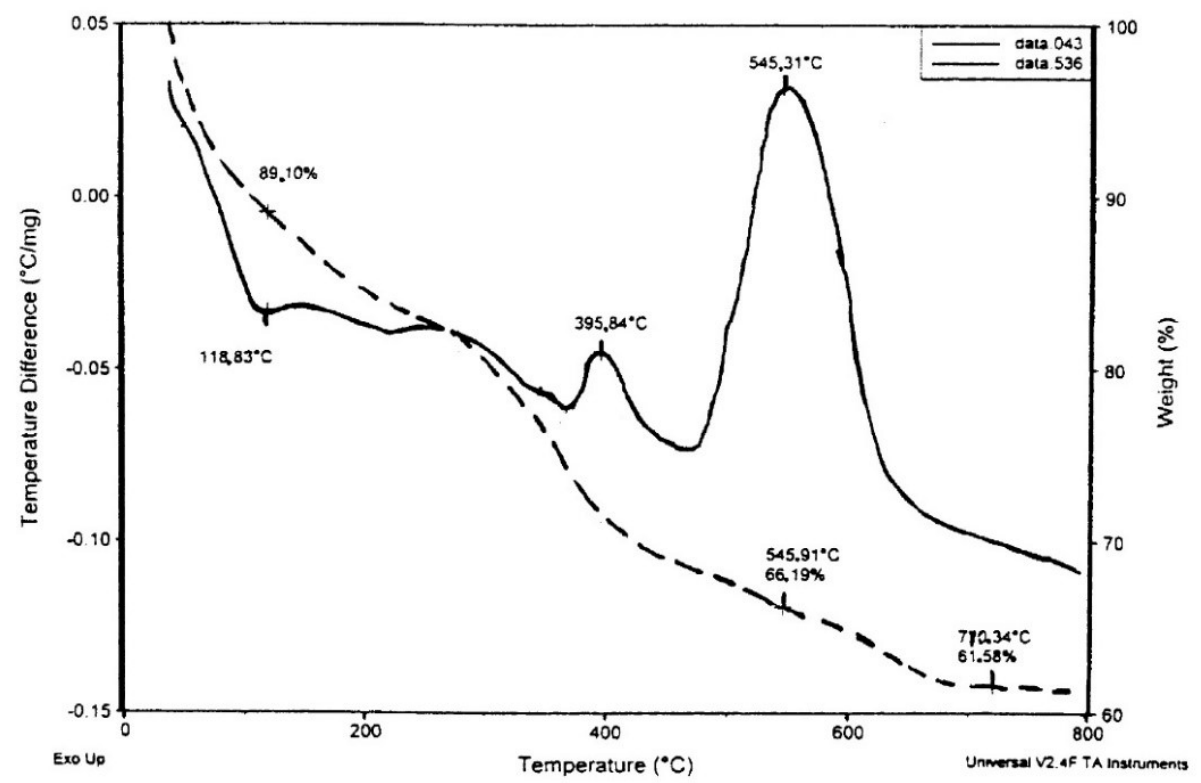

Figure 7. DSC (solid line) and TGA (dashed line) curves of the zirconium acetatecomplex [1]. 

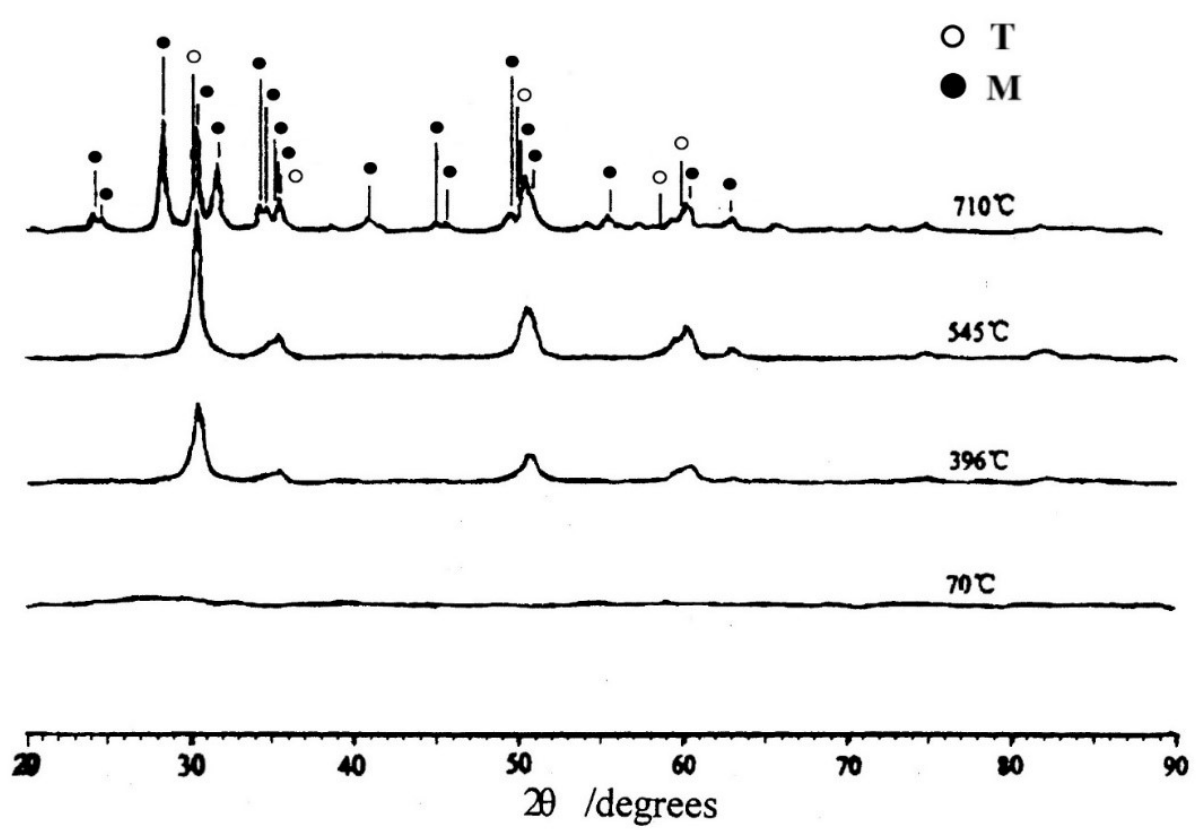

Figure 8. XRD patterns of the zirconium acetate-complex for, (a) as synthesized, calcined at (b) 396 , (c) 545 , and (d) $710^{\circ} \mathrm{C}$ [1].

In 2010, Nayak et. al. published a precipitation synthesis process that utilized $\mathrm{NaBH}_{4}$ as the precipitation agent and $\mathrm{ZrOCl}_{2} \cdot 8 \mathrm{H}_{2} \mathrm{O}$ as the zirconium precursor to produce low temperature $\mathrm{t}-\mathrm{ZrO}_{2}$ with a flake-like morphology [18]. They also included a surfactant, CTAB, to investigate the effects it may have on phase stabilization [18]. This synthesis process was again simplified by adding the $\mathrm{ZrOCl}_{2} \cdot 8 \mathrm{H}_{2} \mathrm{O}$ solution drop-wise to the $\mathrm{NaBH}_{4}$ solution during vigorous stirring until a $\mathrm{pH}$ of 10 was achieved, the CTAB was added to the $\mathrm{ZrOCl}_{2} \cdot 8 \mathrm{H}_{2} \mathrm{O}$ solution before adding to the $\mathrm{NaBH}_{4}$ [18]. The resulting solutions were thoroughly washed with distilled water numerous times until the $\mathrm{pH}$ was that of the distilled water, dried at $80^{\circ} \mathrm{C}$ in an oven, and then ground to a powder with a mortar and pestle [18]. Figure 9 is the DSC results showing similar dehydration characteristics but with very different crystallization peaks past about $500{ }^{\circ} \mathrm{C}$ [18]. Clear and sharp transition peaks were observed in the sample without CTAB, whereas the 
transition peaks were not only broadened but also shifted to higher temperatures for the sample with CTAB [18]. Annealing temperatures of $400,600,700$, and $800{ }^{\circ} \mathrm{C}$ were chosen and XRD analysis was conducted to identify the resulting crystallinity [18]. The as-prepared and $400{ }^{\circ} \mathrm{C}$ annealed samples were found to be amorphous for samples with and without $\mathrm{CTAB}$ [18]. The samples with and without $\mathrm{CTAB}$ annealed at $600{ }^{\circ} \mathrm{C}$ were found to have some $\mathrm{t}-\mathrm{ZrO}_{2}$ crystallites of about $5 \mathrm{~nm}$ in size [18]. Figure 10 is the $\mathrm{XRD}$ results for the $700{ }^{\circ} \mathrm{C}$ samples with and without CTAB [18]. Pure tetragonal phase with an average crystallite size of $15 \mathrm{~nm}$ was found in the CTAB sample. Whereas, majority tetragonal with a small amount (about 5 vol.\%) of monoclinic phase with an average crystallite size of $20 \mathrm{~nm}$ was found in the sample without CTAB [18]. Further increase of the annealing temperature showed an increase in crystallite size and further progression to monoclinic crystalline phase for both samples [18]. These results suggest $\mathrm{CTAB}$ can better stabilize $\mathrm{t}-\mathrm{ZrO}_{2}$ nanoparticles rather than without $\mathrm{CTAB}$, however, it increases the phase transformation temperature to achieve the tetragonal phase. 


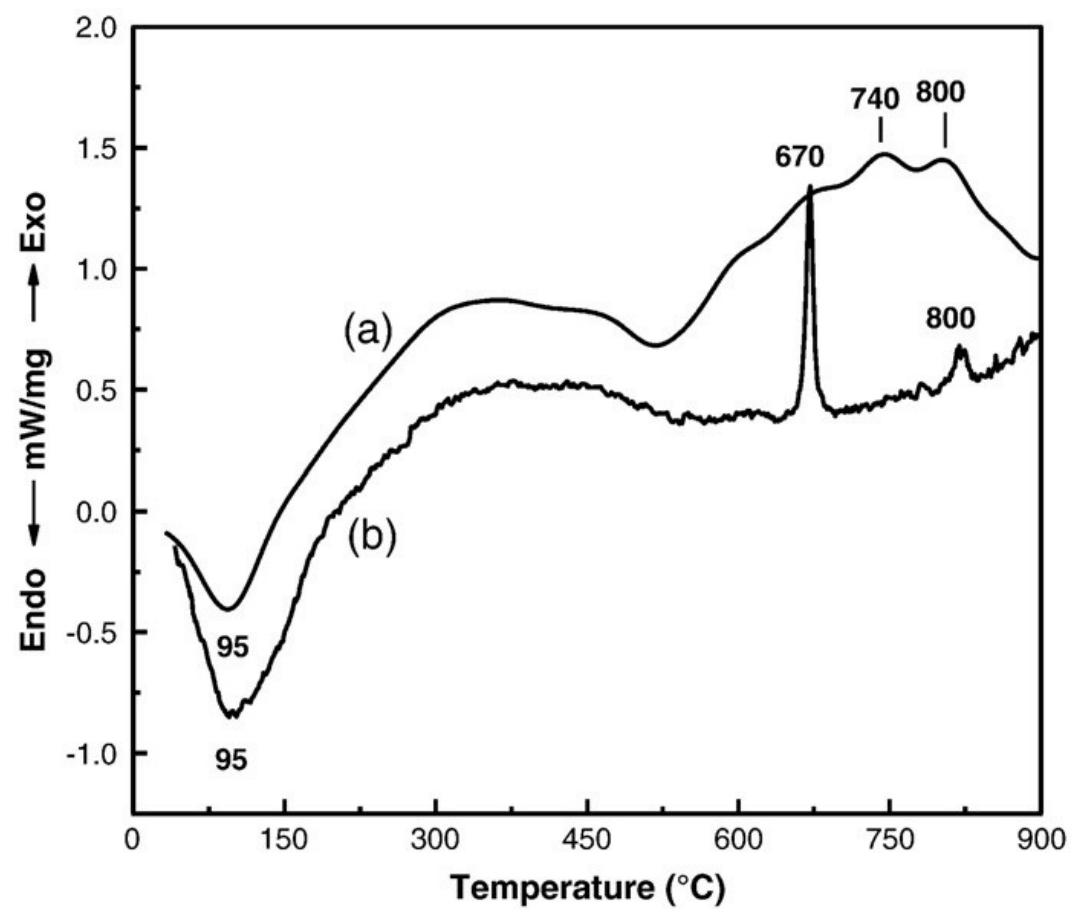

Figure 9. DSC curves for as-synthesized $\mathrm{ZrO}_{2}$ powders (a) with and (b) without CTAB [18].

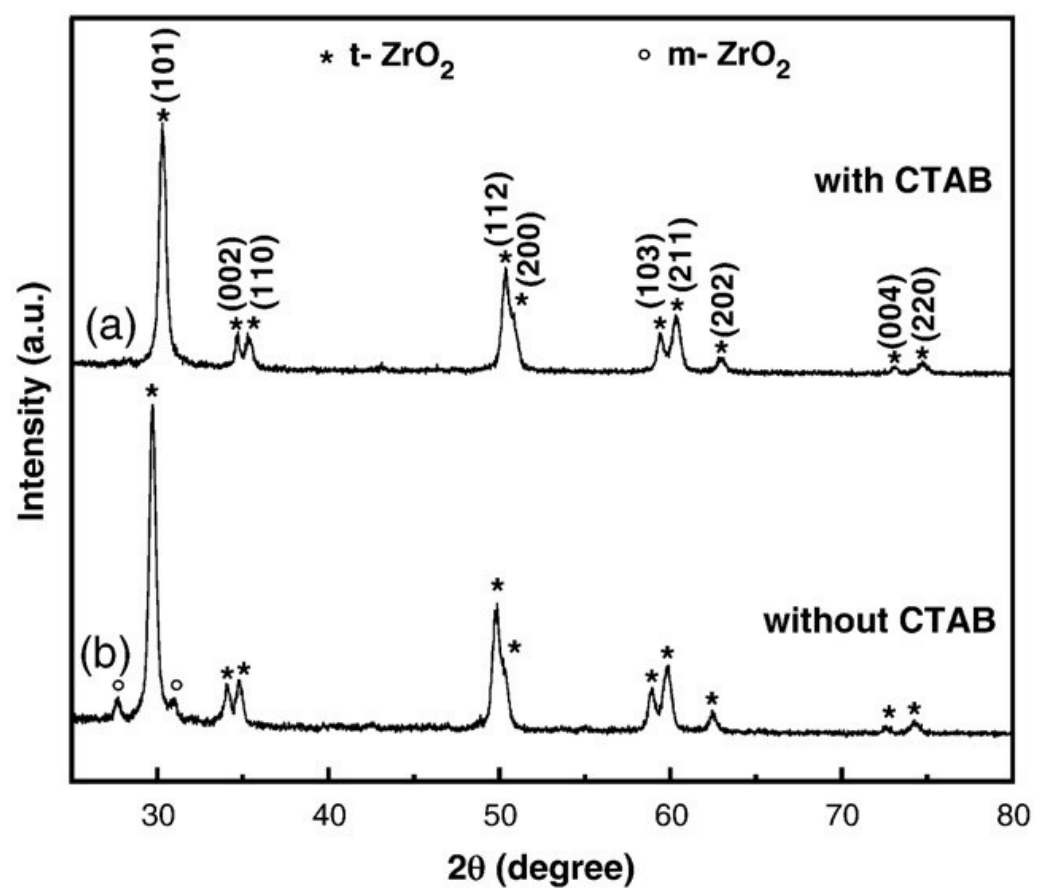

Figure 10. XRD results of $\mathrm{ZrO}_{2}$ powders with and without $\mathrm{CTAB}$ annealed at $700{ }^{\circ} \mathrm{C}$ [18]. 
Nayak et. al. realized the $\mathrm{NaBH} 4$ precipitating agent had an advantage over many other precipitating agents used to produce $\mathrm{ZrO}_{2}$ nanoparticles, which could be applied in industrial and commercial uses [20]. In addition to phase separation to form boron free $\mathrm{ZrO}_{2}$, they observed the borohydride complex evolved hydrogen gas bubbles during precipitation, which resulted in porous $\mathrm{ZrO}_{2}$ nanoparticles that could be used for absorption and storage applications [20]. This study focused on understanding the in-situ hydrogen gas bubble evolution and the resulting absorption performance of $\mathrm{t}-\mathrm{ZrO}_{2}$ for lead ( $\mathrm{Pb}$ II) ion removal in a water solution [20]. A wide pore size distribution between 3.6 to $15.8 \mathrm{~nm}$ was reported with an average pore diameter of $4.6 \mathrm{~nm}$ [20]. Lead ion removal efficiency was reported to be about $99 \%$ in only 15 minutes [20]. Chromium $(\mathrm{Cr}$ VI) ions were also used to determine if there is a diversity to toxic metal ion removal and a reported efficiency of about $10 \%$ suggesting porous $\mathrm{ZrO}_{2}$ was not diverse [20].

\subsection{Ceria-Zirconia Nanomaterials}

In addition to synthesis techniques for production of metastable $\mathrm{ZrO}_{2}$ phases, stabilizers like yittria, magnesia, calcia, and $\mathrm{CeO}_{2}$ can be used with an added bonus of tailoring material properties [5]. Borik et. al. illustrated $\mathrm{t}-\mathrm{ZrO}_{2}$ could be produced by directional melt crystallization growth with 2.8-5.0 mol. \% yttria doping [5]. The resulting PSZ had increased fracture toughness and hardness due to the martensitic transformation toughening to monoclinic phase under increased stress [5].

Quan et.al. looked into the effects europium (Eu) doping would have on $\mathrm{ZrO}_{2}$ [24]. SEM analysis revealed spherical nanoscale particles were made by using a spray pyrolysis and post annealing synthesis technique [24]. XRD analysis showed the onset of 
crystallinity with an annealing temperature as low as $400{ }^{\circ} \mathrm{C}$ and a metastable $\mathrm{t}-\mathrm{ZrO}_{2}$ phase with $\mathrm{Eu}^{3+}$ ions placed in substitutional lattice sites [24]. Photoluminescent intensity was found to increase with increasing annealing temperature with a maximum performance of 10 atomic \% Eu doping [24]. The use of dopants can play a double roll, stabilizing high temperature $\mathrm{ZrO}_{2}$ phases at low temperatures, and tuning material properties for particular applications.

$\mathrm{CeO}_{2}$ has been a popular stabilizing agent for $\mathrm{t}-\mathrm{ZrO}_{2}$ due to high solubility and phase stabilization even at larger grain sizes [25]. Tsukuma and colleague studied the

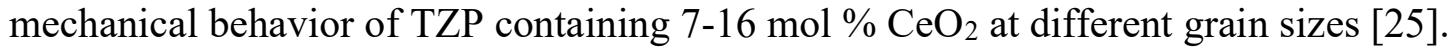
They produced hydrous $\mathrm{CeO}_{2}-\mathrm{ZrO}_{2}$ powders by a hydrolysis method of mixing cerium chloride with zirconyl chloride and heating at $100{ }^{\circ} \mathrm{C}$ for 50 hours [25]. Thermal treatment up to $950{ }^{\circ} \mathrm{C}$ was still able to retain the tetragonal phase which served well for sintering samples for mechanical testing [25]. They found there was an optimal $\mathrm{CeO}_{2}$ concentration for different mechanical properties [25]. The bending strength saw a maximum around $800 \mathrm{MPa}$ when doped with $12 \mathrm{~mol} \% \mathrm{CeO}_{2}$ with a $1.0 \mu \mathrm{m}$ average grain size [25]. The fracture toughness was somewhat opposite with a maximum $\mathrm{K}_{\mathrm{IC}}$ of about $17.5 \mathrm{MNm}^{-1.5}$ at $8 \mathrm{~mol} \% \mathrm{CeO}_{2}$ concentration and $2.5 \mu \mathrm{m}$ average grain size [25]. Lastly, Vickers hardness was found to decrease with increasing average grain size and decreasing $\mathrm{CeO}_{2}$ concentration [25]. The presence of $\mathrm{CeO}_{2}$ not only stabilized the tetragonal phase of $\mathrm{ZrO}_{2}$ at room temperature, but even stabilized when cooled after sintering with resulting large grain growth [25]. Unfortunately, this study did not report 
crystallite size to compare with the observed $30 \mathrm{~nm}$ critical crystallite size for stabilization of $\mathrm{t}-\mathrm{ZrO}_{2}$.

Cerium has played a large roll in modern catalysts due to its oxygen absorption and desorption capability and researchers have investigated the effects of incorporating $\mathrm{CeO}_{2}$ with $\mathrm{ZrO}_{2}$. Chen and colleagues investigated the porous nature of $\mathrm{Ce}-\mathrm{ZrO}_{2}$ materials for possible catalytic applications [49]. BET analysis showed $\mathrm{ZrO}_{2}$ alone had a specific surface area of $362 \mathrm{~m}^{2} \mathrm{~s}^{-1}$ whereas $\mathrm{ZrO}_{2}$ containing $\mathrm{CeO}_{2}$ had $268 \mathrm{~m}^{2} \mathrm{~s}^{-1}$ [49]. $\mathrm{H}_{2}$ absorption analysis gave comparable pore volumes of 0.163 and $0.132 \mathrm{~cm}^{3} \mathrm{~g}^{-1}$ for the pure $\mathrm{ZrO}_{2}$ and $\mathrm{Ce}-\mathrm{ZrO}_{2}$ samples, respectively [49]. And $\mathrm{XRD}$ results showed $\mathrm{CeO}_{2}$ was placed into the substitutional sites of the $\mathrm{ZrO}_{2}$ lattice with a slight reduction in lattice interplanar spacing from 3.14 to $2.97 \mathrm{~nm}$ [49]. It was concluded that the addition of $\mathrm{CeO}_{2}$ into the $\mathrm{ZrO}_{2}$ lattice would reduce the specific surface area while maintaining pore volume suggesting an impact in the pore hysteresis [49].

Aribi et. al. further researched the effects doping $\mathrm{ZrO}_{2}$ with $\mathrm{CeO}_{2}$ would have on structure and catalytic properties [50]. Using a hydrolysis synthesis method, they found increasing the $\mathrm{CeO}_{2}$ concentration and annealing temperature decreased the specific surface area [50]. At the same time, the addition of $\mathrm{CeO}_{2}$ decreased the pore size compared to pure $\mathrm{CeO}_{2}$ or $\mathrm{ZrO}_{2}$ alone [50]. Furthermore, increasing the $\mathrm{CeO}_{2}$ concentration increased the $\mathrm{H}_{2}$ uptake in $\mathrm{H}_{2}$-Temperature Program Reduction (TPR) analysis while increasing annealing temperatures did not show a significant difference [50]. The addition of $\mathrm{CeO}_{2}$ played a majority roll in increasing the absorption of $\mathrm{ZrO}_{2}$ nanoparticles even though the pore size reduced with increasing $\mathrm{CeO}_{2}$ concentration [50]. 
Guillén-Hurtado and coworkers also investigated a $\mathrm{Ce}-\mathrm{ZrO}_{2}$ mixed oxide system to compare two different cerium based precursors for incorporation of $\mathrm{Ce}^{3+}$ and $\mathrm{Ce}^{4+}$ ionic species [51]. Ce- $\mathrm{ZrO}_{2}$ mixed oxides with three different molar ratios $\left(\mathrm{Ce}_{0.8} \mathrm{Zr}_{0.2} \mathrm{O}_{2}\right.$, $\mathrm{Ce}_{0.5} \mathrm{Zr}_{0.5} \mathrm{O}_{2}, \mathrm{Ce}_{0.2} \mathrm{Zr}_{0.8} \mathrm{O}_{2}$ ) along with pure $\mathrm{ZrO}_{2}$ and pure $\mathrm{CeO}_{2}$ were analyzed for this study [51]. The samples with $\mathrm{ZrO}_{2}$ content up to $50 \mathrm{~mol} \%$ using the $\mathrm{Ce}^{4+}$ precursor were found to coprecipitate well, whereas the samples using the $\mathrm{Ce}^{3+}$ precursor had poor insertion of $\mathrm{ZrO}_{2}$ into the lattice system [51]. Calcination at $1000{ }^{\circ} \mathrm{C}$ lead to segregation of tetragonal and cubic phases for the samples using the $\mathrm{Ce}^{3+}$ precursor and a single cubic phase for the samples using the $\mathrm{Ce}^{4+}$ precursor [51]. Greater oxygen mobility was observed in the samples synthesized with the $\mathrm{Ce}^{4+}$ precursor due to a higher number of defects and atomic homogeneity [51].

In another study, Chen et. al. noted that $\mathrm{Ce}-\mathrm{ZrO}_{2}$ material systems could be used as a reactive sorbent for degrading chemical species [27]. Their study focused on synthesis of the $\mathrm{Ce}-\mathrm{ZrO}_{2}$ materials and the degradation of 2-chloroethyle ethyl sulfide (2-CEES), a simulating agent for mustard gas [27]. Table 3 lists the samples that were prepared using a precipitation method with ammonia as the precipitating agent and calcined at $400{ }^{\circ} \mathrm{C}$ for 6 hours [27]. XRD results showed $\mathrm{CeO}_{2}$ cubic-fluorite structure with increasing shift in the 2-theta peaks with increasing $\mathrm{ZrO}_{2}$ concentration indicating $\mathrm{ZrO}_{2}$ assuming substitutional lattice sites [27]. BET and Barrett-Joyner-Halenda (BJH) utilizing nitrogen absorption/desorption isotherm were used to characterize the mesoporous nature of the synthesized samples and the results are listed in Table 3, where the particles were noted to have type IV adsorption isotherms with H3 type porous hysteresis loops [27]. Figure 
11 illustrates the degradation kinetics of 2-CEES where the Ce:Zr atomic ratio of 1:1 degraded $82 \%$ in 4 hours, outperforming all other samples [27]. Even with a different phase structure, the combination of $\mathrm{CeO}_{2}$ and $\mathrm{ZrO}_{2}$ can serve to improve performance for particular applications.

Table 3. Structure and degradation properties for $\mathrm{Ce}-\mathrm{ZrO}_{2}$ co-precipitation material systems [27].

\begin{tabular}{lccccc}
\hline Sample & $\begin{array}{c}\text { Surface area } \\
\left(\mathrm{m}^{2} \mathrm{~g}^{-1}\right)\end{array}$ & $\begin{array}{c}\text { Pore volume } \\
\left(\mathrm{cm}^{3} \mathrm{~g}^{-1}\right)\end{array}$ & $\begin{array}{c}\text { Mean pore } \\
\text { size }(\mathrm{nm})\end{array}$ & $\begin{array}{c}\text { Rate } \\
\text { constant } k_{1} \\
\left(\mathrm{~h}^{-1}\right)\end{array}$ & $\begin{array}{c}\text { Half-life of } \\
\text { 2-CEES } t_{1 / 2} \\
(\mathrm{~h})\end{array}$ \\
\hline $\mathrm{CeO}_{2}$ & 142 & 0.52 & 14.3 & $6.56 \times 10^{-1}$ & 1.06 \\
$\mathrm{Ce}_{0.67} \mathrm{Zr}_{0.33} \mathrm{O}_{2}$ & 156 & 0.34 & 8.1 & $6.98 \times 10^{-1}$ & 0.99 \\
$\mathrm{Ce}_{0.5} \mathrm{Zr}_{0.5} \mathrm{O}_{2}$ & 155 & 0.43 & 10.6 & $4.84 \times 10^{-1}$ & 1.43 \\
$\mathrm{Ce}_{0.33} \mathrm{Zr}_{0.67} \mathrm{O}_{2}$ & 140 & 0.29 & 7.7 & $6.99 \times 10^{-1}$ & 0.99 \\
$\mathrm{ZrO}_{2}$ & 73 & 1.04 & 55.8 & $1.97 \times 10^{-1}$ & 3.52 \\
\hline
\end{tabular}

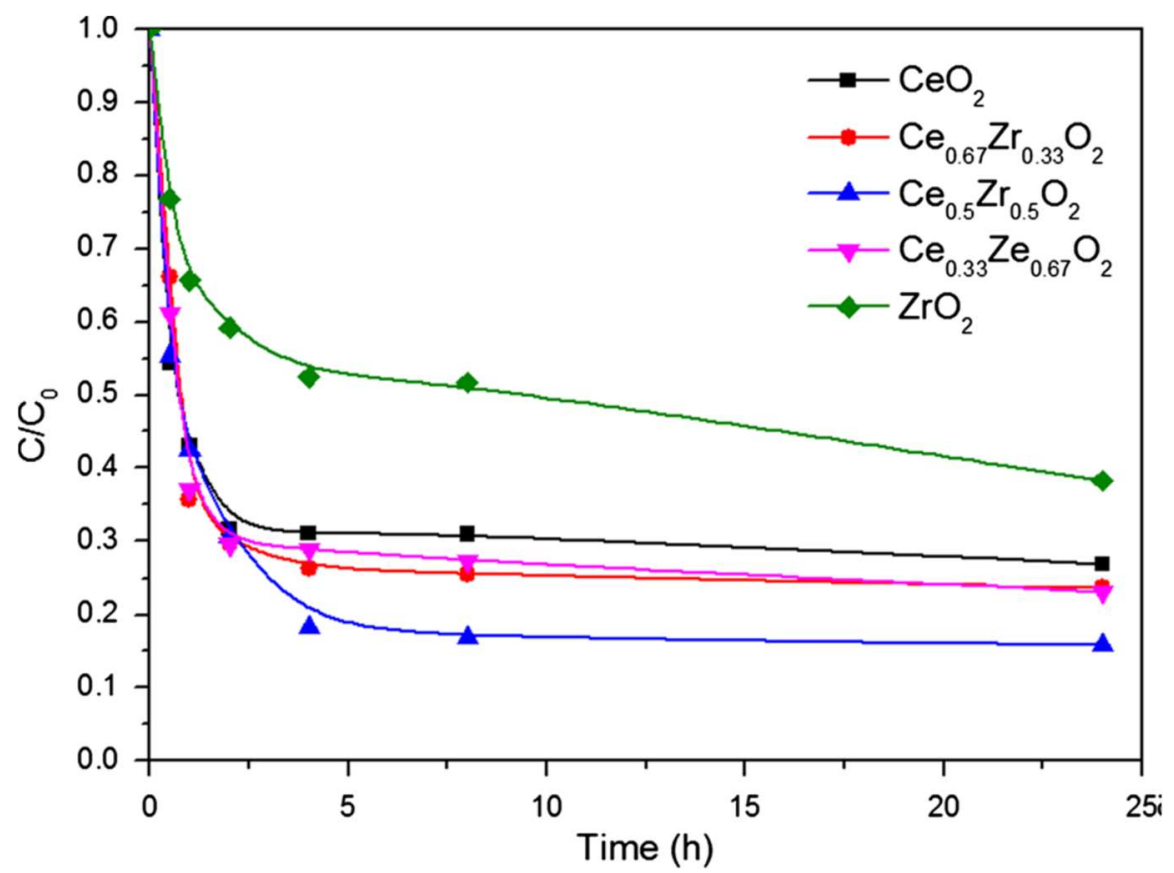

Figure 11. Degradation kinetics of 2-CEES for $\mathrm{Ce}-\mathrm{ZrO}_{2}$ co-precipitation material systems [27]. 


\subsection{Doped Ceria-Zirconia Nanomaterials}

With evidence $\mathrm{Ce}-\mathrm{ZrO}_{2}$ systems had increased material performance, interest turned to further addition of other dopants for even greater material property refinement. Environmentally friendly hydrogen has been proposed as a sustainable fuel that can possibly replace fossil fuels and thus has received large interest in the scientific communities [52]. $\mathrm{Ce}-\mathrm{ZrO}_{2}$ nanomaterials have been found to be a good foundation for hydrogen production by a water splitting reaction [52]. Dasari et. al. researched the enhancement of hydrogen production when a $\mathrm{Ce}-\mathrm{ZrO}_{2}$ system was further doped with rare-earth (RE) metals [52]. Increased hydrogen production was observed when $\mathrm{Ce}-\mathrm{ZrO}_{2}$ composites were doped with either terbium, praseodymium, or lanthanum, with the highest production enhancement from praseodymium at $205 \mu \mathrm{mol} / \mathrm{g}$ [52]. The enhanced performance of praseodymium was further confirmed with the highest oxygen storage capability of $155 \mu \mathrm{mol} / \mathrm{g}$ [52]. Because the systems contained majority $\mathrm{CeO}_{2}(65 \mathrm{~mol} \%)$, XRD results confirmed a cubic-fluorite crystalline structure with the same shifting 2theta peak trend that correlated to the difference in ionic radii of the dopant elements as reported in previous work $[27,52]$. Confirmation the RE dopants were substitutional placed into the $\mathrm{Ce}-\mathrm{ZrO}_{2}$ lattice was obtained by no presence of new peaks in the XRD results [52]. Raman spectroscopy results showed praseodymium had a higher intensity than the other RE dopants signifying an improvement in oxygen mobility and in turn catalytic activity which correlated with the oxygen storage and hydrogen production results [52]. 
Oxygen storage capability of $\mathrm{Ce}-\mathrm{ZrO}_{2}$ composites have become a point of focus for researchers due to higher performance in purification of immersion gases like carbon monoxide and hydrocarbons [31]. Fan et. al. studied the oxygen storage capability of Ce$\mathrm{ZrO}_{2}$ systems with a 2:1 ratio when modified by either coprecipitation or impregnation of 3 mass percent strontium ( $\mathrm{Sr}$ ) and when thermally aged or not [31]. All samples were annealed at $700{ }^{\circ} \mathrm{C}$ and $\mathrm{XRD}$ analysis indicated a cubic-fluorite crystalline phase [31]. The thermally aged samples were further annealed at $1050{ }^{\circ} \mathrm{C}$ for 5 hours and the sharpening of the XRD peaks indicated sintering of the powders [31]. In addition, the presence of new peaks indicated segregation of $\mathrm{CeO}_{2}$ and $\mathrm{ZrO}_{2}$ rich phases [31]. The sintering and segregation effects from thermal aging were reduced by the addition of $\mathrm{Sr}$ by either introduction method but the impregnation method showed greater thermal stability [31]. The correlation between reducibility and activation energy were observed in this study when the aged $\mathrm{Sr}$ impregnated $\mathrm{Ce}-\mathrm{ZrO}_{2}$ samples had the greatest reducibility and greatest oxygen storage capacity (OSC) [31]. Because segregation was observed in this sample, it was suspected that the interface between $\mathrm{SrZrO}_{2}$ and $\mathrm{CeO}_{2}-\mathrm{ZrO}_{2}$ offered the greatest oxygen mobility and held highly active oxygen species resulting in maximum performance [31]. Having a secondary alloying phase, such as the impregnated $\mathrm{Sr}$ in this case, could serve to help tailor the overall material performance for particular applications. The implementation of further system doping and secondary phase doping has the possibility of enhancing $\mathrm{Ce}-\mathrm{ZrO}_{2}$ performance and tailoring the systems properties for particular applications. 


\subsection{Carbon, Graphene and Quantum Dots}

Due to being environmentally friendly and because it is abundantly available, carbonbased materials have received great interest in research communities. Research into carbon- $\mathrm{ZrO}_{2}$ nanocomposites and other material systems were used to gain some insight for developing this project due to the infancy of GQDs and limited published research. Kaur et. al. investigated the hydrogen storage capability of $\mathrm{ZrO}_{2}$ and reduced graphene oxide nanocomposites for applications in fuel cell and similar technologies [35]. Enhanced hydrogen storage capacity for $\mathrm{ZrO}_{2}$-reduced graphene oxide versus graphene oxide was found to be due to the changes in surface area and porosity [35]. They observed an increase in surface area from $14.3 \mathrm{~m} 2 / \mathrm{g}$ for graphene oxide to $390 \mathrm{~m} 2 / \mathrm{g}$ for $\mathrm{ZrO}_{2}$-reduced graphene oxide [35]. Additionally, they observed a decrease in pore size distribution from $5.38 \mathrm{~nm}$ for graphene oxide to $2.56 \mathrm{~nm}$ for $\mathrm{ZrO}_{2}$-reduced graphene oxide [35]. Some insight this research offered was the increase in thermal stability and presence of oxygen functional groups with the $\mathrm{ZrO}_{2}$-graphene oxide composite system [35], suggesting reasonable investigation into thermal stability and preservation of functional groups for $\mathrm{ZrO}_{2}-\mathrm{GQD}$ composite systems.

The work done by Rani et. al. offered further supporting evidence for thermal stability and preservation of functional groups for $\mathrm{ZrO}_{2}$-graphene composite systems [32]. Zirconia oxychloride precursor in a precipitation and reflux synthesis method with post annealing treatments up to $1000^{\circ} \mathrm{C}$ was used to produce the $\mathrm{ZrO}_{2}$-graphene composite [32]. Their work showed the addition of graphene to $\mathrm{ZrO}_{2}$ increased the photocatalytic activity of $\mathrm{ZrO}_{2}$ for the degradation of methyl orange with increasing 
content of graphene in the composite system [32]. It was stated that the enhancement in the photocatalytic activity was due to graphene creating electron hole pairs without the ability of recombination, offering more available sites for the photo catalytic reaction to take place [32]. They also reported photocatalytic reactions increased when the annealing temperature increased [32], offering some reasonable suggestion that GQDs could be thermally stable in a $\mathrm{ZrO}_{2}$ based support and remain after synthesis and thermal treatments.

GQDs are a relatively new founded material and has been projected to have a profound impact for industrial applications due its unique properties [36]. In 2014, Bacon et. al. published an overview covering up-to-date research for synthesis, properties, and applications of GQDs [36]. At that time, GQDs were synthesized by two generally categized methods, either top-down or bottom-up methods [36]. The top-down method generally starts with converting a graphite based material to graphite oxide sheets by some form of the Hummers method with a mixture of sulfuric acid, sodium nitrate, and potassium permanganate, or similar chemistry [36]. At this point, several different methods could be utilized for converting the graphene oxide sheets to GQDs such as: hydrothermal cutting, solvochemical cutting, electrochemical cutting, nanolithography, microwave-assisted cutting, nanotomy-assisted exfoliation, and ultrasonic shearing [36]. Generally speaking, the alternative bottom-up approach involves pyrolysis of an acid, like citric acid, to produce graphite followed by carbonization, or oxidation exfoliation, to yield GQDs [36]. Bacon covered a stepwise organic synthesis technique where oxidation of polyphenylene dendritic precursors produced large colloidal GQDs [36]. Another 
bottom-up approach given was cage opening of fullerenes where catalyzed ruthenium gave attachment sites for C60 to embed on the surface and post annealing treatments agglomerated the carbon clusters to produce GQDs [36].

GQDs hold extraordinary properties, most notable is quantum confinement that results in a non-zero bandgap and luminesce upon excitation [36]. By modification of GQDs with different functional groups and densities, the photoluminescence spectrum can be tailored in the range of ultraviolet to near-infrared [36]. It was noted that one of the most attractive aspects of GQDs was they are a carbon material that are abundantly available, have low toxicity, highly soluble, and can be easily modified by functional groups, making them viable alternative substitutes over their inorganic counterparts for applications [36].

Electrooxidation of graphene to produce GQDs has been promised as an environmentally friendly approach that avoids the use of high temperatures and chemically hazardous reagents [42]. Luo et. al. published new findings for GQDs synthesized using this electrooxidation method, producing GQDs with average diameters of about $52 \mathrm{~nm}$ that have photoluminescence excitation wavelength-independent properties [42]. This contradicted earlier findings and motivated Luo to investigate further [42]. By synthesizing more GQDs and using a dialysis bag to separate particle sizes, it was found that this synthesis method also produced smaller sizes of several nanometers that were found to be wavelength-dependent, showing a size dependence on the photoluminescence capability [42]. 
The implementation of GQDs into polymeric material systems have shown to enhance some material properties while suppressing others, suggesting the ability to tailor composites for particular applications [46]. Using a polymer composite of cellulose acetate and GQDs, Arthisree et. al. observed a change in structural, mechanical, optical and electrical properties as a function of GQD concentration [46]. An increase in crystallinity and a decrease in direct band gap was observed with increasing GQD content, resulting in increased photoluminescence intensities with increased GQDs [46]. Shore A softness results showed a decrease with increasing GQD concentration [46]. SEM and TEM analysis showed dispersion of the GQDs in the polymer matrix, which supported the overall change in the softness results due to well distributed GQDs [46]. Gobi et. al. also showed changes in mechanical properties as a function of GQD concentration in an epoxy matrix [45]. A $225 \%$ increase in tensile strength, compared to pure epoxy, was reported at a 2.5 weight percent concentration of GQDs [45]. Additionally, an $18 \%$ increase to the tensile stain, despite the increase in tensile strength, and a 2.5 times increase in the Young's modulus was found with the addition of GQDs into the epoxy matrix [45]. These examples suggest the implementation of GQDs as a secondary phase addition to material systems can enhance many material properties.

All this research leaves the question, how do GQDs behave in oxides and compounds? A recently published article investigating the enhancement of photocatalytic properties when anatase $\mathrm{TiO}_{2}$ is doped with GQDs offers some insight to the effects GQDs can have in ceramic nanocomposites [47]. By exfoliation of bird charcoal at varying temperatures, different sized GQDs were created and UV-vis 
spectroscopy showed a slight red shift in the emission spectrum as a function of increasing GQD particle size [47]. Photoluminescence spectroscopy showed thermal treatment had little impact on the emission spectrum of QGDs but the highest photoluminescence intensity was found at $635 \mathrm{~nm}$ wavelength with an excitation at 580 nm [47]. However, doping TiO2 with GQDs showed a dependence of GQD concentration on the photoluminescence intensity, increased doping concentration resulted in increased intensity, and it was suggested incorporation of GQDs induced more defect sites that resisted electron hole pair recombination [47]. The photocatalytic properties were conducted by degradation of methylene blue where the presence of GQDs enhanced the photocatalytic performance [47]. $\mathrm{TiO}_{2}$ doped with 1 wt.\% GQDs showed the greatest degradation with the highest calculated rate constant relative to the other doped samples and pure $\mathrm{TiO}_{2}[47]$. 


\section{CHAPTER THREE \\ RESEARCH OBJECTIVE}

\section{$3.1 \quad$ Objective}

The objective of this thesis was to investigate the processing and structure of $\mathrm{Ce}-\mathrm{ZrO}{ }_{2}$ nanoparticles doped with GQDs when derived by the $\mathrm{NaBH}_{4}$ precipitation method. $\mathrm{Ce}-$ $\mathrm{ZrO}_{2}$ material systems have been researched extensively, however there appeared to be some gaps in research regarding the optimization of the materials performance with respect to synthesis routes. In addition, GQD doping has shown to enhance performance of some material systems but due to infancy of GQDs, much research was still needed. Several key publications served as guidance for the focus and development of this thesis.

\subsection{Justification}

Previous research has shown low temperature stabilized $\mathrm{t}-\mathrm{ZrO}_{2}$ nanoparticles produced by an aqueous $\mathrm{NaBH}_{4}$ precipitation method enhanced porosity and surface area over other synthesis methods due to in-situ hydrogen gas evolution $[19,20]$. In addition, a coprecipitation of $\mathrm{Ce}-\mathrm{ZrO}_{2}$ nanocomposites, produced by a different synthesis method, showed enhancements in porosity and surface area [27]. There did not appear to be studies in the literature covering coprecipitation of $\mathrm{Ce}-\mathrm{ZrO}_{2}$ nanocomposites that used the $\mathrm{NaBH}_{4}$ synthesis method, which raised the question whether $\mathrm{NaBH}_{4}$ synthesis of Ce$\mathrm{ZrO}_{2}$ nanocomposites would result in additional enhancements compared to either one.

$\mathrm{CeO}_{2}$ and $\mathrm{ZrO}_{2}$ share some similar mechanical, thermal, and electrical properties that have been found useful in applications like polishing media, thermal barriers and fuel cells. Combination of the two have shown to enhance other properties such as catalytic 
activities, which enhanced stabilization of the lattice and in turn allowed further extent of the reaction to take place [30]. With increased lattice stability during reactions when combining $\mathrm{CeO}_{2}$ and $\mathrm{ZrO}_{2}$, and with increased porosity and surface area from the use of the $\mathrm{NaBH}_{4}$ precipitation method, it was hypothesized that performance enhancements in properties like chemisorption, gas storage-production, and conductivity would be a result.

Due to the infancy of GQDs, much research still remained for the impact this relatively new material could have in applications. Research has shown enhancements to mechanical, optical, and electrical properties of polymer-based GQD composite materials $[43,45,46]$ and $\mathrm{ZrO}_{2}$-based graphene composite materials [33,35]. The only published research found which offered some insight to the effect GQDs have on ceramic based systems was the enhancement of optical and catalytic properties of $\mathrm{TiO}_{2}$ doped with GQDs [47]. From these research efforts, it was suspected GQDs could tailor optical, electrical, and chemical properties of $\mathrm{Ce}-\mathrm{ZrO}_{2}$ composites while enhancing structural and mechanical properties.

Using these resources to project an outcome for this thesis study, $\mathrm{NaBH}_{4}$ derived GQD doped $\mathrm{Ce}-\mathrm{ZrO}_{2}$ nanocomposites could have compounded enhancements in electrical, chemical, optical, and mechanical properties. Furthermore, $\mathrm{NaBH}_{4}$ precipitation route offers a simple and environmentally friendly synthesis process from abundantly available resources. With little to no hazardous byproducts, this synthesis route could be a viable alternative to other production methods used in commercial applications. 


\section{CHAPTER FOUR}

\section{MATERIALS AND METHODS}

In order to develop this work of process and characterization of GQD doped $\mathrm{Ce}-\mathrm{ZrO} 2$ nanocomposites, several aspects were addressed. Sample preparation, experimental plan, and equipment needed were addressed in the experimental setup, apparatus and supplies sections below. The safety section covers all safety consideration, including protective equipment, lab environment, and chemical handling. The analytical instrument and data analysis section covers the tools used to collect data and the methods used to analyze the data, respectively.

\subsection{Experimental Setup}

Samples were produced by mixing aqueous solutions of $\mathrm{NaBH}_{4}$ with aqueous solutions containing $\mathrm{CeO}_{2}, \mathrm{ZrO}_{2}$, and GQD precursors in a previous study. Brief, processing is as follows: a 5 molar aqueous solution of $\mathrm{NaBH}_{4}$ was prepared by adding the appropriate volume of deionized (DI) water to the appropriate weight of solid $\mathrm{NaBH}_{4}$ ( $\geq 98.0 \%$ grade), the actual volume and weight depended on the total amount of each sample needed for analysis. Three different categories of precursors were used for this study, one for pure $\mathrm{ZrO}_{2}$, one for $16 \mathrm{~mol} \% \mathrm{Ce}-\mathrm{ZrO}_{2}$, and one for $16 \mathrm{~mol} \% \mathrm{Ce}-\mathrm{ZrO}_{2}$ containing GQDs. To study the effects functional group may have on the $\mathrm{Ce}-\mathrm{ZrO}_{2}$ systems, aminate and carboxylate GQDs were used. For pure $\mathrm{ZrO}_{2}$ samples, a 0.5 molar aqueous solution of $\mathrm{ZrO}_{2}$ was prepared by adding the appropriate volume of DI water to the appropriate weight of $\mathrm{ZrOCl}_{2} \cdot 8 \mathrm{H}_{2} \mathrm{O}\left(99.5 \%\right.$ grade). For Ce- $\mathrm{ZrO}_{2}$ samples, a 0.5 molar aqueous solution was prepared by adding the appropriate volume of DI water to the 
appropriate weight of cerium chloride heptahydrate $\left(\mathrm{CeCl}_{3} \cdot 7 \mathrm{H}_{2} \mathrm{O}-99.5 \%\right.$ grade $)$ and $\mathrm{ZrO}_{2}$ oxychloride octahydrate. Equation 2 was used to calculate the weight of each component needed with respect to the volume of solution, where $\mathrm{x}$ is the mole percent of cerium projected to be in each sample. To add the GQDs, a 25 grams per liter solution of GQDs in DI water was used in substation of the DI water described above in the $\mathrm{CeO}_{2}$ and $\mathrm{ZrO}_{2}$ precursors. Equation 3 was the calculation for the amount of GQD solution used when preparing the precursors, where y is the GQD concentration (in grams per liter of solution) and $\mathrm{x}$ is mol $\%$ of cerium projected to be in each sample.

$$
\begin{array}{ll}
\mathrm{Ce}_{\mathrm{x}} \mathrm{Zr}_{1-\mathrm{x}} \mathrm{O}_{2}=1.686 \frac{\text { grams }\left(\mathrm{CeCl}_{3} \cdot 7 \mathrm{H}_{2} \mathrm{O}\right)}{\mathrm{L} \text { solution }} * \mathrm{x}+1.611 \frac{\text { grams }\left(\mathrm{ZrOCl}_{2} \cdot 8 \mathrm{H}_{2} \mathrm{O}\right)}{\mathrm{L} \text { solution }} *(1-\mathrm{x}) & \text { Equation } 2 \\
\mathrm{Wt} \% \% \mathrm{GQD}=\frac{\mathrm{y}}{\mathrm{y}+86.059 \frac{\text { grams }}{\mathrm{L} \mathrm{solution}}\left(\mathrm{CeO}_{2}\right) * \mathrm{x}+61.611 \frac{\text { grams }}{\mathrm{L} \mathrm{solution}}\left(\mathrm{ZrO}_{2}\right) *(1-\mathrm{x})} & \text { Equation 3 }
\end{array}
$$

The synthesis process to produce the GQD-Ce- $\mathrm{ZrO}_{2}$ nanocomposite samples is outlined in the flow diagram in Figure 12. To prepare a sample batch, a precursor solution was added dropwise to a $\mathrm{NaBH}_{4}$ solution at room temperature. During addition of the precursor, the mixture was manually stirred vigorously to ensure thorough mixing. After stirring, the solution was left to settle the precipitate particles to the bottom of the containment, where then a transfer pipet was used to remove the bulk of the aqueous boron complex byproduct. DI water was added to the solution to dilute the boron complex, effectively rinsing the precipitated particles. The particles were allowed to settle and the bulk diluted boron complex byproduct was removed, again by a transfer pipet. These two steps, dilution with DI water and removal of the diluted boron complex byproduct, were repeated until the solution $\mathrm{pH}$ was that of the DI water. The rinsed precipitates were dried in an oven at $80{ }^{\circ} \mathrm{C}$ for 24 hours to remove as much moisture as 
possible. Finally, the dried precipitates were ground with a pestle and mortar to form a fine powder.

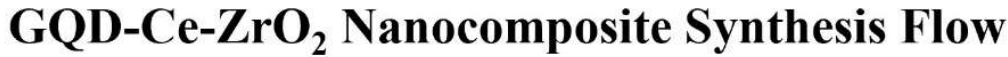

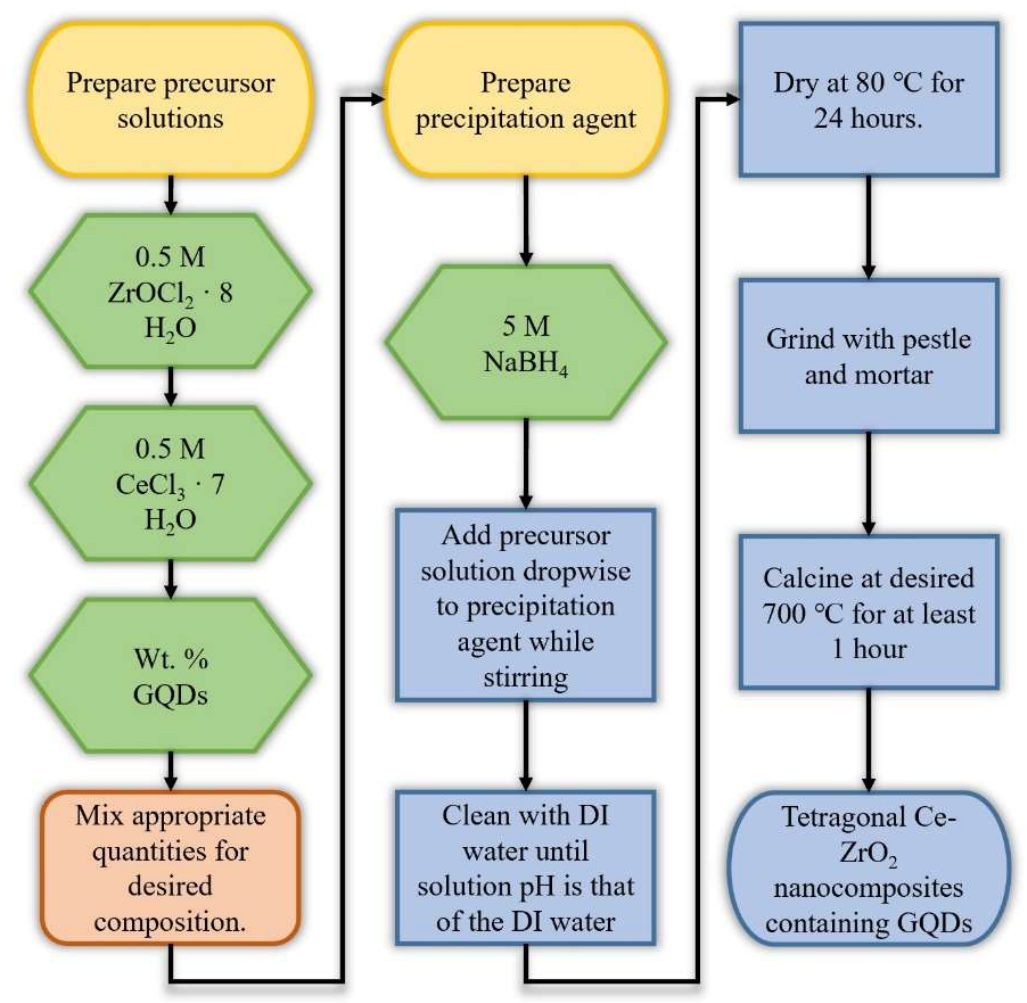

Figure 12. Process flow diagram to produce GQD doped Ce-ZrO2 nanocomposites.

To achieve crystallinity of the synthesized samples, each needed to be calcined at elevated temperatures. Table 4 is the sample matrix showing the $\mathrm{Ce}-\mathrm{ZrO}_{2}$ composition, the GQDs content, and the various calcine temperatures. Each sample was calcined for 1 hour. Alumina crucibles were chosen for the thermal treatment because it could be easily traced to the annealing process if contamination issues were observed during chemical analysis. A KP-type thermocouple was used to calibrate and monitor the furnace temperature. 
Table 4. Sample matrix for GQD weight percent concentrations and calcination temperatures.

\begin{tabular}{lcc}
\hline Composition & $\begin{array}{c}\text { GQD Content } \\
\text { (wt. } \%)\end{array}$ & $\begin{array}{c}\text { Calcine } \\
\text { Temperature }\left({ }^{\circ} \mathbf{C}\right)\end{array}$ \\
\hline $\mathrm{ZrO}_{2}$ & 0 & $\begin{array}{c}400,500,650,700, \\
\text { and } 800\end{array}$ \\
$\mathrm{ZrO}_{2}$ with amine GQD & 3 and 7 & 700 \\
$\mathrm{Ce}_{0.16} \mathrm{Zr}_{0.84} \mathrm{O}_{2}$ & 0 & 700 \\
$\mathrm{Ce}_{0.16} \mathrm{Zr}_{0.84} \mathrm{O}_{2}$ with amine GQD & 0.1 and 0.5 & 700 \\
$\mathrm{Ce}_{0.16} \mathrm{Zr}_{0.84} \mathrm{O}_{2}$ with carboxyl GQD & 0.1 and 0.5 & 700 \\
\hline
\end{tabular}

\subsection{Apparatus and Supplies}

Starting with synthesis of the samples, typical chemical lab equipment was needed. First and foremost, a fume hood with greater than 100 feet per minute face velocity was used for all chemical work. Glass beakers were used to contain the solutions and a scale was used to measure the quantities of the solid chemicals for each batch. Spatulas, pipets, and graduated cylinders were used to handle the solid chemicals and measure the volumes of DI water and GQD solutions. $\mathrm{ZrOCl}_{2} \cdot 8 \mathrm{H}_{2} \mathrm{O}(99.5 \%$ grade $), \mathrm{CeCl}_{3} \cdot 7 \mathrm{H}_{2} \mathrm{O}$ (99.5\% grade), and $\mathrm{NaBH}_{4}(\geq 98.0 \%$ grade) were all procured from Sigma-Aldrich. The GQD solutions were obtained from ACS Materials. A glass stirrer was used for both preparation of the precursor solutions and mixing of those solutions used to produce the precipitate particles.

To complete the synthesis process, a low temperature oven was used to dry the resulting samples. Then a pestle and mortar were used to grind the samples to a fine 
powder. While the samples were ground after drying, a 3M N95 breathing mask was used for inhalation protection because this process could not be done in a fume hood.

The thermal treatment process required the use of a high temperature furnace.

Thermal barrier gloves, eye protection, and long metal tongs were used for safe handling. Alumina crucibles were used to contain the samples and KB-type thermocouples were used to monitor the furnace temperature.

\subsection{Safety}

In the production of GQD doped $\mathrm{Ce}-\mathrm{ZrO}_{2}$ nanocomposites, possible touch contact and inhalation were of primary safety concerns. To address the possible touch contact risks, personal protective equipment (PPE) of goggles, gloves, and a lab coat were worn at all times during synthesis, thermal treatment, and sample analysis preparation steps. To address the inhalation safety risks, a fume hood was used during chemical handling and synthesis of the samples. During the grind to powder samples and handling while preparing for analysis, a 3M N95 particle mask was used. The safety data sheets (SDS) for each chemical was obtained from either the source it was purchased from or the manufacture of that particular chemical. The chemical hazard ratings, recommended PPE, and other safety considerations, like chemical compatibilities, obtained from each SDS are tabulated in Table 5. Since the addition of water to $\mathrm{NaBH}_{4}$ evolves hydrogen gas, which is flammable, a fume hood was used, any non-needed ignition sources were removed from the vicinity, and an $\mathrm{ABC}$ fire extinguisher was available in case needed. Both eye wash and safety shower stations were confirmed to be operational before any lab work. Spill clean-up kits were confirmed to be present and properly stocked. 
Table 5. Summary of hazard ratings, PPE and noteworthy information from the SDS for each chemical used in this study.

\begin{tabular}{|c|c|c|c|c|c|}
\hline Chemical & $\begin{array}{c}\text { Health } \\
\text { Hazard } \\
\text { Rating }\end{array}$ & $\begin{array}{l}\text { Flamm- } \\
\text { ability } \\
\text { Rating }\end{array}$ & $\begin{array}{c}\text { Reactivity } \\
\text { Hazard } \\
\text { Rating }\end{array}$ & PPE & Other \\
\hline $\begin{array}{l}\text { Zirconium } \\
\text { Oxychloride } \\
\text { Octahydrate }\end{array}$ & 3 & 0 & 0 & $\begin{array}{l}\text { Gloves, } \\
\text { Goggles, } \\
\text { Lab coat }\end{array}$ & $\begin{array}{c}\text { Incompatibility with } \\
\text { strong oxidizing } \\
\text { agents }\end{array}$ \\
\hline $\begin{array}{l}\text { Cerium } \\
\text { Chloride } \\
\text { Heptahydrate }\end{array}$ & 2 & 0 & 0 & $\begin{array}{l}\text { Gloves, } \\
\text { Goggles, } \\
\text { Lab coat }\end{array}$ & $\begin{array}{c}\text { Incompatibility with } \\
\text { strong oxidizing } \\
\text { agents and acids }\end{array}$ \\
\hline $\begin{array}{l}\text { Sodium } \\
\text { Borohydride }\end{array}$ & 3 & 4 & 2 & $\begin{array}{l}\text { Gloves, } \\
\text { Goggles, } \\
\text { Lab coat }\end{array}$ & $\begin{array}{l}\text { Contact with water } \\
\text { produces flammable } \\
\text { gas, use fume hood }\end{array}$ \\
\hline $\begin{array}{l}\text { Graphene } \\
\text { Quantum } \\
\text { Dots }\end{array}$ & 0 & 0 & 0 & $\begin{array}{l}\text { Gloves, } \\
\text { Goggles, } \\
\text { Lab coat }\end{array}$ & \\
\hline $\begin{array}{l}\text { Isopropyl } \\
\text { Alcohol 99\% } \\
\text { Grade }\end{array}$ & 1 & 3 & 0 & $\begin{array}{l}\text { Gloves, } \\
\text { Goggles, } \\
\text { Lab coat }\end{array}$ & $\begin{array}{l}\text { Use with vapor } \\
\text { respirator or fume } \\
\text { hood }\end{array}$ \\
\hline
\end{tabular}

Touch contact and inhalation safety were also of concern during the thermal treatment process. The PPE used for this process consisted of latex gloves, goggles, and a lab coat. Since the samples were in powder form at this time a 3M N95 particle mask was used to protect against inhalation hazard. To protect against burn related risks, thermal barrier mitts and coat, face shield, and tongs were used during loading and unloading of samples in the furnaces. Each furnace used was inspected for safe operation and the main fuses were located in case power needed to be shut off in an emergency. 


\subsection{Analytical Instruments and Data Analysis}

The various samples in this study were analyzed for their thermal events, crystalline structure, material composition, bonding states, particle morphology, and lattice parameters. The analytical techniques used to obtain this information were DSC/TGA, XRD, XPS, SEM and TEM. The experimental matrix showing the analytical techniques used for each sample composition, GQD content, and thermal treatment are outlined in Table 6.

Table 6. Experimental matrix of analytical techniques used for each sample composition, GQD content, and thermal treatment.

\begin{tabular}{|c|c|c|c|c|c|c|c|}
\hline Composition & $\begin{array}{c}\text { GQD } \\
\text { Content } \\
\text { (wt. \%) }\end{array}$ & $\begin{array}{l}\text { Calcine } \\
\text { Temp. } \\
\left({ }^{\circ} \mathrm{C}\right)\end{array}$ & $\begin{array}{c}\text { DSC } \\
\& \\
\text { TGA }\end{array}$ & XRD & XPS & SEM & TEM \\
\hline \multirow{6}{*}{$\mathrm{ZrO}_{2}$} & \multirow{6}{*}{0} & Unannealed & $\sqrt{ }$ & $\sqrt{ }$ & \multirow{6}{*}{$\sqrt{ }$} & \multirow{6}{*}{$\sqrt{ }$} & \multirow{6}{*}{$\sqrt{ }$} \\
\hline & & 400 & & $\sqrt{ }$ & & & \\
\hline & & 500 & & $\sqrt{ }$ & & & \\
\hline & & 650 & & $\sqrt{ }$ & & & \\
\hline & & 700 & & $\sqrt{ }$ & & & \\
\hline & & 800 & & $\sqrt{ }$ & & & \\
\hline \multirow{2}{*}{$\begin{array}{l}\mathrm{ZrO}_{2} \text { with amine } \\
\text { GQD }\end{array}$} & 3 & $\begin{array}{c}\text { Unannealed } \\
700\end{array}$ & $\sqrt{ }$ & $\sqrt{ }$ & $\sqrt{ }$ & $\sqrt{ }$ & $\sqrt{ }$ \\
\hline & 7 & $\begin{array}{c}\text { Unannealed } \\
700\end{array}$ & $\sqrt{ }$ & & \multicolumn{3}{|c|}{$\sqrt{ }$} \\
\hline $\mathrm{Ce}_{0.16} \mathrm{Zr}_{0.84} \mathrm{O}_{2}$ & 0 & $\begin{array}{c}\text { Unannealed } \\
700\end{array}$ & $\sqrt{ }$ & $\sqrt{ }$ & $\sqrt{ }$ & $\sqrt{ }$ & $\sqrt{ }$ \\
\hline \multirow{2}{*}{$\begin{array}{l}\mathrm{Ce}_{0.16} \mathrm{Zr}_{0.84} \mathrm{O}_{2} \text { with } \\
\text { amine GQD }\end{array}$} & 0.1 & $\begin{array}{c}\text { Unannealed } \\
700\end{array}$ & $\sqrt{ }$ & $\sqrt{ }$ & $\sqrt{ }$ & $\sqrt{ }$ & $\sqrt{ }$ \\
\hline & 0.5 & $\begin{array}{c}\text { Unannealed } \\
700\end{array}$ & $\sqrt{ }$ & $\sqrt{ }$ & $\sqrt{ }$ & $\sqrt{ }$ & $\sqrt{ }$ \\
\hline \multirow{2}{*}{$\begin{array}{l}\mathrm{Ce}_{0.16} \mathrm{Zr}_{0.84} \mathrm{O}_{2} \text { with } \\
\text { carboxyl GQD }\end{array}$} & 0.1 & $\begin{array}{c}\text { Unannealed } \\
700\end{array}$ & $\sqrt{ }$ & $\sqrt{ }$ & $\sqrt{ }$ & $\sqrt{ }$ & $\sqrt{ }$ \\
\hline & 0.5 & $\begin{array}{c}\text { Unannealed } \\
700\end{array}$ & $\sqrt{ }$ & $\sqrt{ }$ & $\sqrt{ }$ & $\sqrt{ }$ & $\sqrt{ }$ \\
\hline
\end{tabular}




\subsubsection{Thermal Analysis}

DSC and TGA were conducted using a Perkin Elmer Simultaneous Thermal Analyzer STA8000 with nitrogen gas flow. The tool's specifications were $0.2 \mu \mathrm{g}$ balance resolution, $0.5{ }^{\circ} \mathrm{C}$ temperature accuracy and $5 \%$ calorimetric accuracy. The temperature range tested for each sample was $30-1200{ }^{\circ} \mathrm{C}$ at a heating rate of $10{ }^{\circ} \mathrm{C}$ per minute. Alumina crucibles were used for thermal stability throughout the tested temperature range and about 10-15 mg of each sample were used per test. Weight loss of the samples was monitored by the TGA mode where the change in the weight versus temperature was recorded. The weight loss at particular temperatures was used to identify particular thermal events such as dehydration, evaporation, and decomposition. Heat flow in the samples was monitored by the DSC mode, where the difference in heat between the sample and an empty reference crucible was recorded. The difference in heat flow between the reference and sample crucibles indicated a thermal event such as a phase transformation. The plain $\mathrm{ZrO}_{2}$ sample was tested to serve as a base to compare with the different $\mathrm{Ce}-\mathrm{ZrO}_{2}$ and GQD samples. The $\mathrm{Ce}-\mathrm{ZrO}_{2}$ sample was tested to correlate against the GQD doped samples to observe the effect GQDs had on crystal formation and phase transformation. Each of the GQD containing samples were tested to observe any effects on crystal formation and phase transformation with respect to GQD concentration. The tests were conducted at Perkin Elmer's facility in San Jose, CA, where training and supervision was provided by Dr. Jun Wang. I conducted the tests and analysis. 


\subsubsection{X-Ray Diffractometry}

XRD was conducted using a Rigaku Ultima III XRD with a copper K $\alpha$ radiation source operating at $40 \mathrm{kV}$ and $44 \mathrm{~mA}$. A scanning velocity of $6^{\circ}$ per minute recording data at every $0.01^{\circ}$ intervals over a range of $20<\theta<80^{\circ}$ was used with a detection limit of 1 wt. \%. ICDD cards were used with MDI's Jade software to identify the observed diffraction peaks. The intensity of the diffracted x-ray beam was recorded versus the angle at which they were detected and peaks of high intensity were used to identify particular crystalline structures. XRD was also chosen to determine if $\mathrm{CeO}_{2}$ and $\mathrm{ZrO}_{2}$ mixed oxides were made or if coprecipitation occurred for the various samples. The PPE used were safety goggles, latex gloves, lab coat, and a 3M N95 particle mask. The tests were conducted at the $\mathrm{MC}^{2}$ Metrology Center at San Jose State University. Samples were prepared and loaded by myself and scans conducted by Dr. Craig England.

\subsubsection{X-Ray Photoelectron Spectroscopy}

The chemical composition and bonding states were characterized by XPS using a Thermo Scientific K-Alpha system with a detection limit of 0.1-0.2 at. \% equipped with an Al Ka x-ray source under ultra-high vacuum. A $400 \mu \mathrm{m}$ spot size was used with a take-off angle of 90 degrees and sample charging was compensated with an electron flood gun. Each sample powder was placed on a coin of indium foil and gently pressed to hold in place and flatten for analysis. The PPE used were safety goggles, latex gloves, lab coat, and a 3M N95 particle mask. The C 1s, Ce 3d, Ce 4d, Mg 1s, O 1s, Zr 3d, and $\mathrm{Zr} 3 \mathrm{p}$ core levels were recorded for each sample. All samples annealed at $700{ }^{\circ} \mathrm{C}$ were analyzed using this spectroscopy technique. Each sample composition was obtained and 
compared to the expected theoretical composition, outlined in Equation 2 and Equation 3. The XPS tests were conducted at Nanolab Technologies facility in Milpitas, CA, where sample preparation and analysis was conducted by Dr. Jeff Gold.

\subsubsection{Scanning Electron Microscopy}

Particle morphology was studied using a FEI Nova NanoSEM 630 equipped with a field emission electron gun at or lower than $5 \mathrm{kV}$ with a resolution of $1.6 \mathrm{~nm}$. For sample preparation, the PPE used were safety goggles, latex gloves, lab coat, and a 3M N95 particle mask. The powder samples were diluted in Isopropyl Alcohol (IPA) and sonicated for 30 minutes to further disperse the particles. Then a pipet was used to place a drop on a sample stub which then was placed under a heat lamp to evaporate the IPA. SEM images were obtained as data from this analysis and used to characterize particle morphology, particle size, and degree of agglomeration. SEM inspection was conducted at Nanolab Technologies facility in Milpitas, CA, where I prepared and analyzed the samples.

\subsubsection{Transmission Electron Microscopy}

TEM analysis was done at two different facilities. The first facility was Nanolab Technologies in Milpitas, CA were a JOEL 2100 High Resolution Transmission Electron Microscope (HRTEM) operating at $200 \mathrm{kV}$ with a $0.8 \mathrm{~nm}$ resolution was used. The second facility was EAG Laboratories in Sunnyvale, CA were a FEI Tecnai TF-20 FEG/TEM operating at $200 \mathrm{kV}$ with a $0.6 \mathrm{~nm}$ resolution was used. Bright-Field (BF), High-Resolution (HR), and High-Angle Annular Dark-Field (HAADF) Scanning TEM (STEM) modes were used. For sample preparation, the PPE used were safety goggles, 
latex gloves, lab coat, and a 3M N95 particle mask. Similar to the SEM sample preparation, each sample was diluted in IPA, sonicated for 30 minutes, and a drop was placed on a copper grid coated with a holey carbon film and dried under a heat lamp. TEM images and diffraction patterns were obtained as data from this analysis and used to characterize particle size, nanostructures, atom and lattice distances, and presence of GQDs. The images were analyzed using Digital Micrograph version 3.22 and atom to atom distances were measured and compared to theoretical values. The theoretical values were calculated from Vegard's Law, shown in Equation 4, were A represents $\mathrm{CeO}_{2}, \mathrm{~B}$ represents $\mathrm{ZrO}_{2}$, $\mathrm{x}$ represents the mole percent of cerium, and a is the lattice parameter in angstroms.

$$
\mathrm{a}_{\mathrm{AxB}(1-\mathrm{x})}=(\mathrm{x}) \mathrm{a}_{\mathrm{A}}+(1-\mathrm{x}) \mathrm{a}_{\mathrm{B}} \quad \text { Equation } 4
$$

In addition to microscopy with TEM, chemical analysis was conducted using a Tecnai ChemiSTEM EDS with a detection limit of 1 at. $\%$ on the FEI TEM. The EDS analysis was processed with Bruker Quantax software. Sample preparation was completed by myself and operation of the TEM and image acquisition was done by Dr. Zhou Yang at Nanolab Technologies and Yulia Grozman at EAG Laboratories. 


\section{CHAPTER FIVE}

\section{RESULTS AND DISCUSSION}

\subsection{Thermal Analysis}

The DSC and TGA curves showed the release of physically absorbed water, released hydroxyl $\left(\mathrm{OH}^{-}\right)$groups, and the crystallization for each sample. The DSC and TGA curves for samples $\mathrm{ZrO}_{2}, \mathrm{Ce}-\mathrm{ZrO}_{2}, \mathrm{Ce}-\mathrm{ZrO}_{2}$ with amine GQDs, and $\mathrm{Ce}-\mathrm{ZrO}_{2}$ with carboxyl GQDs, both containing 0.5 wt. \% GQDs, are represented in Figure 13 and Figure 14, respectively. The first peak, endothermic, shown in the DSC curves of Figure 13 occurred between $63{ }^{\circ} \mathrm{C}$ and $73{ }^{\circ} \mathrm{C}$, which represented the release of physically absorbed water. The first TGA weight loss step, correlating to the first DSC peak, seen in Figure 14 ranged approximately 6 to 9 wt. \% confirmed the desorption of physically absorbed water. The second peak, endothermic, seen in the DSC curves occurred between approximately $188^{\circ} \mathrm{C}$ and $258^{\circ} \mathrm{C}$ and correlated with the second TGA weight loss step (Figure 14). In addition to the continuation of water desorption, this second weight loss step represented the removal of $\mathrm{OH}^{-}$groups, forming $\mathrm{ZrO}_{2}$ from $\mathrm{Zr}(\mathrm{OH})_{4}$. The third DSC peak, exothermic, occurred between approximately $660{ }^{\circ} \mathrm{C}$ and $717^{\circ} \mathrm{C}$ and correlated with the third weight loss step in the TGA curves. The third peak represents the crystallization of the $\mathrm{ZrO}_{2}$ matrix and will be further explained in the next section.

Table 7 tabulates the weight loss percent for each TGA step and the DSC peak temperatures for $\mathrm{ZrO}_{2}, \mathrm{Ce}-\mathrm{ZrO}_{2}$, and both amine and carboxyl GQD doped samples with both 0.1 and 0.5 wt. \% content. The addition of $\mathrm{CeO}_{2}$ to $\mathrm{ZrO}_{2}$ reduced the overall 
amount of weight loss, as seen in Figure 14. The presence of $\mathrm{CeO}_{2}$ or GQDs did not appear to influence the amount of physically absorbed water or the amount of $\mathrm{OH}^{-}$groups released during heating. For example, the $\mathrm{Ce}-\mathrm{ZrO}_{2}$ sample showed a higher desorption of water than the $\mathrm{ZrO}_{2}$ sample during the first TGA step, whereas all other samples containing $\mathrm{CeO}_{2}$ desorbed less water with the exception of $0.5 \mathrm{wt} . \%$ amine GQD doped $\mathrm{Ce}-\mathrm{ZrO}{ }_{2}$ sample, which was similar to the $\mathrm{ZrO}_{2}$ sample. The same lack of trend amongst all samples and their associated weight loss stages suggested either dopants are independent of weight loss or there was a lack of control during the synthesis process. The former is less likely when absorption/desorption has been shown to be influenced by dopants in $\mathrm{ZrO}_{2}$ systems [31]. Both the first and second DSC endothermic peaks correlating to the first and second weight loss steps did not show a trend between samples, nor appear influenced significantly by primary or secondary dopants. However, the most notable dopant dependency on thermal events was during crystallization, the exothermic event in the third DSC peak. The presence of $\mathrm{CeO}_{2}$ affected the onset of crystallization, indicated by the arrow in Figure 13 at the lower temperature values at the exothermic peaks. The addition of $\mathrm{CeO}_{2}$ reduced the crystallization temperature by about $40{ }^{\circ} \mathrm{C}$, from $700{ }^{\circ} \mathrm{C}$ for $\mathrm{ZrO}_{2}$ to about $660{ }^{\circ} \mathrm{C}$ for all samples except the $0.1 \mathrm{wt} . \%$ amine and carboxyl GQD doped samples. The lowering of the transformation temperature with $\mathrm{CeO}_{2}$ doping is in agreement with others findings $[27,51,52]$ and the discrepancy with the 0.1 wt. \% GQD doped samples was believed to be due to low synthesis control. The presence of GQDs did not appear to affect the weight loss trend or phase transformation. 


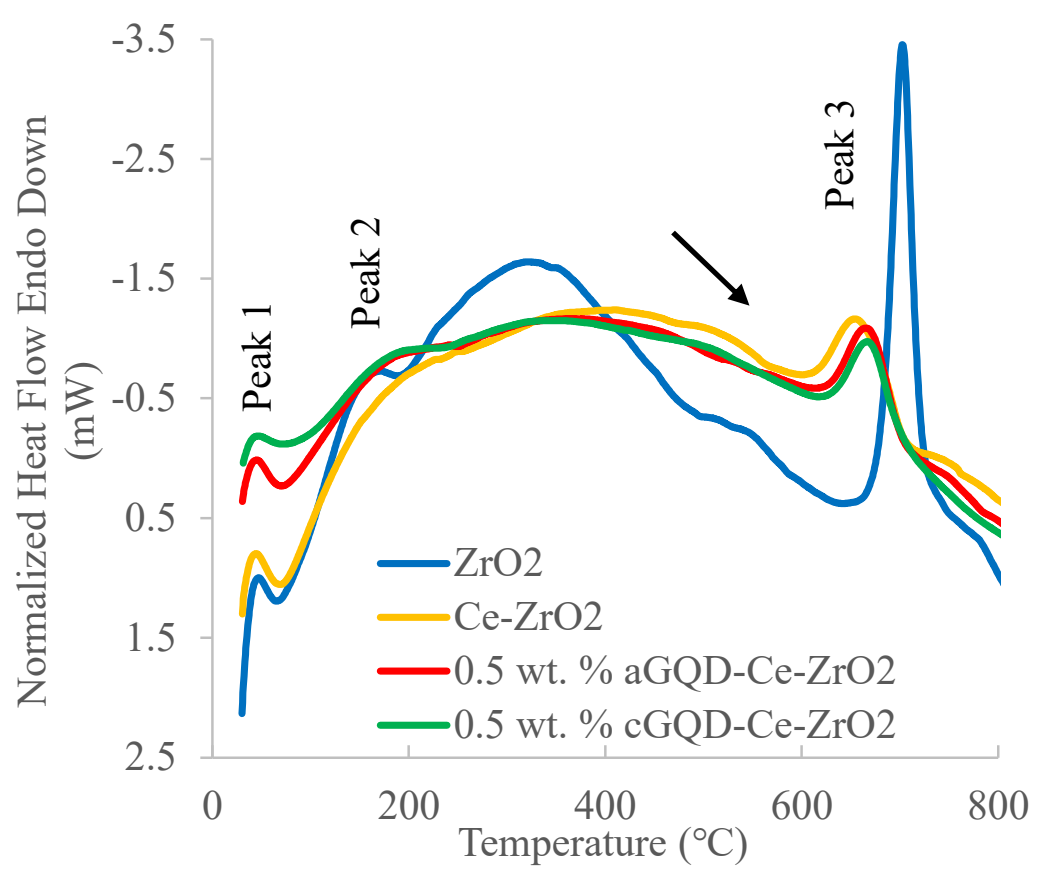

Figure 13. Normalized DSC results for $\mathrm{ZrO}_{2}, \mathrm{Ce}-\mathrm{ZrO}_{2}, 0.5$ wt. \% amine GQD-Ce- $\mathrm{ZrO}_{2}$, and 0.5 wt. $\%$ carboxyl GQD-Ce- $\mathrm{ZrO}_{2}$ samples.

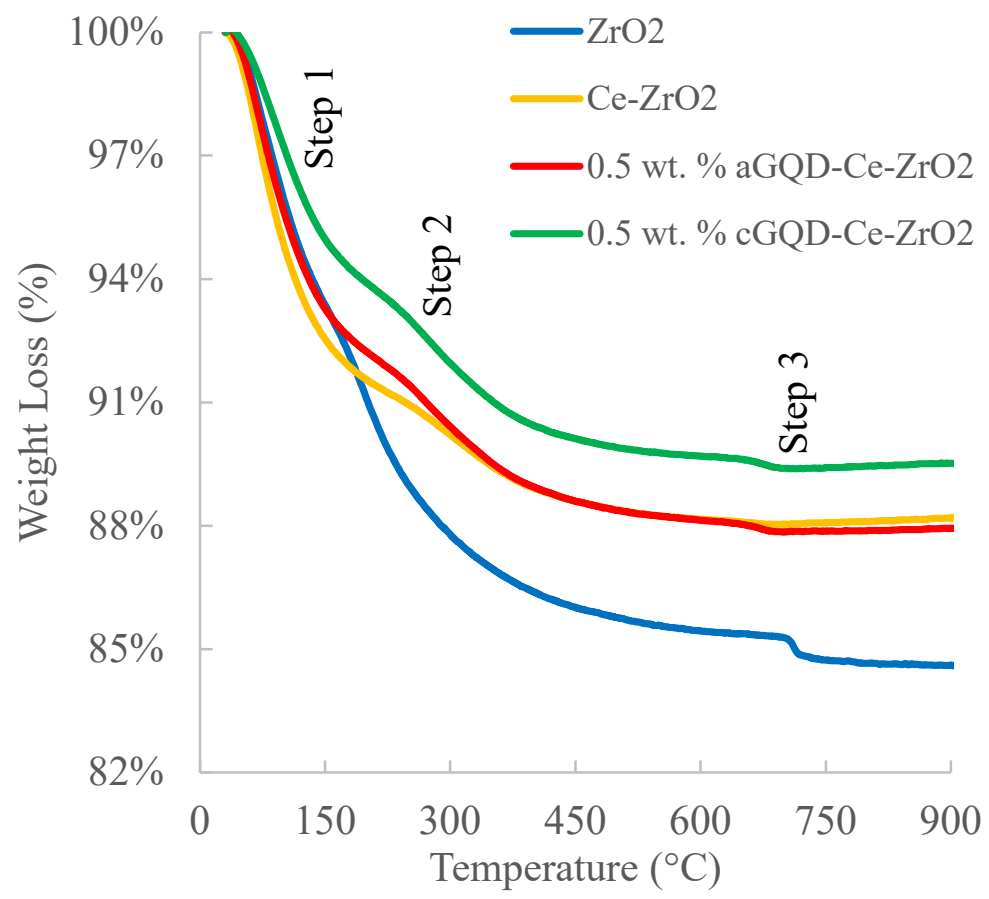

Figure 14. TGA weight loss percent results for $\mathrm{ZrO}_{2}, \mathrm{Ce}-\mathrm{ZrO}_{2}, 0.5$ wt. \% amine GQD$\mathrm{Ce}-\mathrm{ZrO}_{2}$, and 0.5 wt. \% carboxyl GQD-Ce- $\mathrm{ZrO}_{2}$ samples. 
Table 7. TGA weight loss steps and DSC events peaks tabulated for $\mathrm{ZrO}_{2}, \mathrm{Ce}-\mathrm{ZrO}$, and $\mathrm{Ce}-\mathrm{ZrO}_{2}$ samples doped with either amine or carboxyl GQDs at both 0.1 and $0.5 \mathrm{wt} . \%$.

\begin{tabular}{|c|c|c|c|c|c|c|}
\hline \multirow{2}{*}{ Sample } & \multicolumn{3}{|c|}{ TGA Weight Loss (wt. \%) } & \multicolumn{3}{|c|}{ DSC Event Peaks $\left({ }^{\circ} \mathrm{C}\right)$} \\
\hline & Step 1 & Step 2 & Step 3 & Peak 1 & Peak 2 & Peak 3 \\
\hline $\mathrm{ZrO}_{2}$ & 8.035 & 6.694 & 0.671 & 65.42 & 188.35 & 701.88 \\
\hline $\mathrm{Ce}_{0.16} \mathrm{Zr}_{0.84} \mathrm{O}_{2}$ & 9.066 & 2.742 & 0.109 & 68.88 & 257.56 & 661.88 \\
\hline $\begin{array}{l}\mathrm{Ce}_{0.16} \mathrm{Zr}_{0.84} \mathrm{O}_{2} \text { with } 0.1 \\
\text { wt. } \% \text { amine GQD }\end{array}$ & 7.752 & 6.453 & 0.542 & 87.23 & 207.27 & 716.64 \\
\hline $\begin{array}{l}\mathrm{Ce}_{0.16} \mathrm{Zr}_{0.84} \mathrm{O}_{2} \text { with } 0.1 \\
\text { wt. } \% \text { carboxyl GQD }\end{array}$ & 7.166 & 6.370 & 1.501 & 61.12 & 194.99 & 705.58 \\
\hline $\begin{array}{l}\mathrm{Ce}_{0.16} \mathrm{Zr}_{0.84} \mathrm{O}_{2} \text { with } 0.5 \\
\text { wt. } \% \text { amine GQD }\end{array}$ & 8.195 & 3.749 & 0.247 & 67.93 & 241.33 & 666.89 \\
\hline $\begin{array}{l}\mathrm{Ce}_{0.16} \mathrm{Zr}_{0.84} \mathrm{O}_{2} \text { with } 0.5 \\
\text { wt. } \% \text { carboxyl GQD }\end{array}$ & 6.695 & 3.432 & 0.294 & 72.69 & 239.44 & 666.61 \\
\hline
\end{tabular}

\subsection{Crystallographic Analysis}

In addition to observing the crystalline transition with increasing temperature, XRD was used to confirm the tetragonal crystalline phase after thermal treatment for all the doped $\mathrm{ZrO}_{2}$ samples. Figure 15 shows the increase in crystallinity for pure $\mathrm{ZrO}_{2}$ annealed at $400{ }^{\circ} \mathrm{C}, 600{ }^{\circ} \mathrm{C}$ and $700{ }^{\circ} \mathrm{C}$, where amorphous to tetragonal crystalline structure was observed. Both $400{ }^{\circ} \mathrm{C}$ and $600{ }^{\circ} \mathrm{C}$ showed no significant peaks indicating amorphous structure. However, $700{ }^{\circ} \mathrm{C}$ showed clear crystalline peaks that correlate to t$\mathrm{ZrO}_{2}$ crystalline structure. To observe any phase dependency on doping of $\mathrm{ZrO}_{2}, \mathrm{XRD}$ was performed on all samples. Results for the $\mathrm{ZrO}_{2}, \mathrm{Ce}-\mathrm{ZrO}{ }_{2}, \mathrm{Ce}-\mathrm{ZrO}_{2}$ with amine or carboxyl GQDs, containing either 0.1 or 0.5 wt. \% GQDs are represented in Figure 16. 
The XRD analysis confirmed $\mathrm{t}-\mathrm{ZrO}_{2}$ crystalline structure for all samples annealed at 700 ${ }^{\circ} \mathrm{C}$. The crystallite size and lattice parameters are tabulated in Table 8 showing the addition of Ce reduced the crystallite size and increased the interplanar spacing. This was due to the larger ionic radius of cerium $(0.097 \mathrm{~nm})$ compared to zirconium $(0.084$ $\mathrm{nm})$, resulting in stretching the lattice structure and suppressing the crystalline growth. This observation was in agreement with other research [49]. Pure $\mathrm{ZrO}_{2}$ had a crystal size of approximately $19 \mathrm{~nm}$, whereas all samples containing Ce were approximately $15 \mathrm{~nm}$ in size. There did not appear to be any discernible effects from the presence of GQDs.

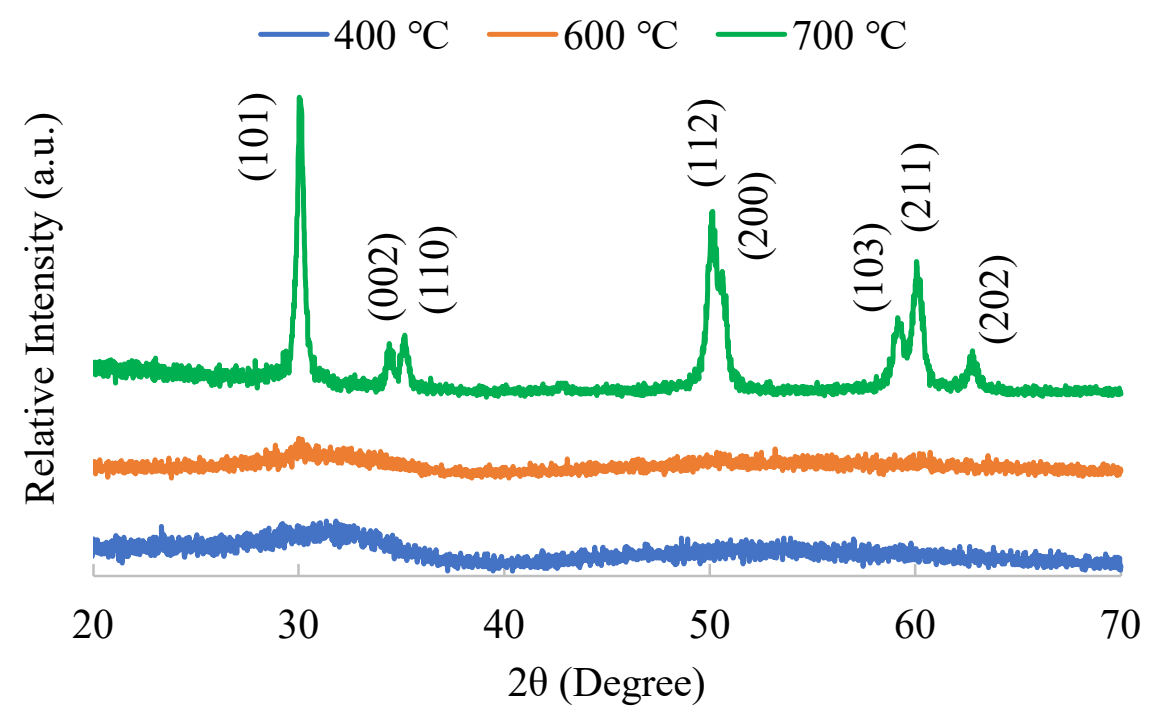

Figure 15. Onset of crystallinity with increased annealing temperature of $\mathrm{ZrO}_{2}$ by XRD. 


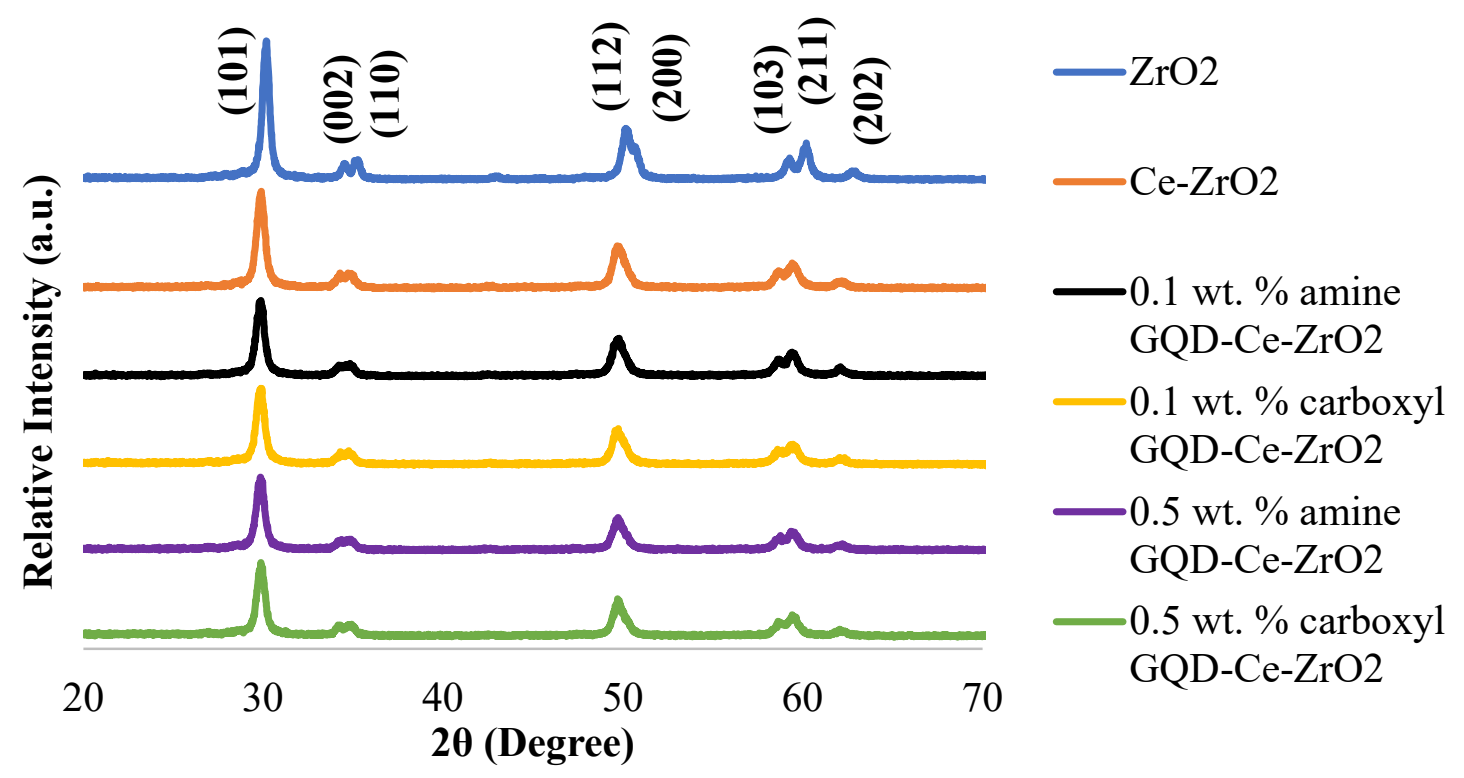

Figure 16. XRD intensity peaks for $\mathrm{ZrO}_{2}, \mathrm{Ce}-\mathrm{ZrO} \mathrm{rO}_{2}, \mathrm{Ce}-\mathrm{ZrO}_{2}$ with amine GQDs or carboxyl GQDs, containing either 0.1 or $0.5 \mathrm{wt}$ \% GQDs, all annealed at $700{ }^{\circ} \mathrm{C}$.

Table 8. Lattice parameter values tabulated for samples calcined at $700{ }^{\circ} \mathrm{C}$.

\begin{tabular}{|c|c|c|c|}
\hline \multirow{2}{*}{ Samples } & \multirow{2}{*}{$\begin{array}{l}\text { Crystallite } \\
\text { Size (nm) }\end{array}$} & \multicolumn{2}{|c|}{ Experimental Lattice Parameters } \\
\hline & & $\mathrm{a}=\mathrm{b}(\AA)$ & c $(\AA)$ \\
\hline $\mathrm{ZrO}_{2}$ & $19.4 \pm 0.4$ & 3.596 & 5.138 \\
\hline $\mathrm{Ce}-\mathrm{ZrO}_{2}$ & $14.6 \pm 0.3$ & 3.635 & 5.227 \\
\hline 0.1 wt. $\%$ amine GQD-Ce- $\mathrm{ZrO}_{2}$ & $15.4 \pm 0.3$ & 3.637 & 5.227 \\
\hline 0.1 wt. $\%$ carboxyl GQD-Ce- $\mathrm{ZrO}_{2}$ & $14.8 \pm 0.3$ & 3.636 & 5.229 \\
\hline 0.5 wt. $\%$ amine GQD-Ce- $\mathrm{ZrO}_{2}$ & $14.3 \pm 0.3$ & 3.636 & 5.228 \\
\hline 0.5 wt. $\%$ carboxyl GQD-Ce- $\mathrm{ZrO}_{2}$ & $15.0 \pm 0.3$ & 3.635 & 5.226 \\
\hline
\end{tabular}




\subsection{Compositional Analysis}

XPS analysis for all samples revealed the concentration of Ce to be $13-14$ at. $\%$ for each sample, 2-3 at. \% lower than targeted 16 at. \% Ce for the precipitation reaction. Table 9 covers $\mathrm{ZrO}_{2}, \mathrm{Ce}-\mathrm{ZrO}_{2}$, and $\mathrm{Ce}-\mathrm{ZrO}_{2}$ samples doped with either amine or carboxyl GQDs at both 0.1 and 0.5 wt. \%. Trace sodium and magnesium were detected and were attributed to be remanence from the synthesis process or contamination during annealing or sample preparation. The presence of GQDs did not show any significant impact on the stoichiometry of the composite samples. There was no consistent elevation of carbon detected by XPS with the samples containing GQDs, nor between samples with increased GQD concentration. XPS did not offer conclusive evidence to the presence of GQDs remaining after synthesis.

Table 9. Compositional and $\mathrm{Ce}-\mathrm{ZrO}_{2}$ ratio results from XPS analysis.

\begin{tabular}{|c|c|c|c|c|c|c|c|}
\hline \multirow{2}{*}{ Sample } & \multicolumn{6}{|c|}{ Composition (at. \%) } & \multirow{2}{*}{$\begin{array}{c}\mathrm{Ce} \\
/ \mathrm{CeZr} \\
(\%)\end{array}$} \\
\hline & Ce $3 d$ & Zr 3d & $\mathrm{O} 1 \mathrm{~s}$ & $\mathrm{C} 1 \mathrm{~s}$ & $\mathrm{Na} 1 \mathrm{~s}$ & $\operatorname{Mg} 1 \mathrm{~s}$ & \\
\hline $\mathrm{ZrO}_{2}$ & 0.0 & 17.1 & 82.0 & 0.4 & 0.0 & 0.4 & 0.0 \\
\hline $\mathrm{Ce}-\mathrm{ZrO}_{2}$ & 2.4 & 15.6 & 81.4 & 0.6 & 0.0 & 0.1 & 13.3 \\
\hline $\begin{array}{l}0.1 \text { wt. } \% \text { amine } \\
\text { GQD-Ce- } \mathrm{ZrO}_{2}\end{array}$ & 2.4 & 15.6 & 81.9 & 0.0 & 0.1 & 0.0 & 13.3 \\
\hline $\begin{array}{l}0.1 \text { wt. \% carboxyl } \\
\text { GQD-Ce- } \mathrm{ZrO}_{2}\end{array}$ & 2.5 & 15.6 & 81.6 & 0.2 & 0.0 & 0.0 & 13.8 \\
\hline $\begin{array}{l}0.5 \text { wt. } \% \text { amine } \\
\text { GQD-Ce- } \mathrm{ZrO}_{2}\end{array}$ & 2.4 & 15.6 & 81.3 & 0.5 & 0.0 & 0.2 & 13.3 \\
\hline $\begin{array}{l}0.5 \text { wt. \% carboxyl } \\
\text { GQD-Ce- } \mathrm{ZrO}_{2}\end{array}$ & 2.6 & 16.3 & 80.3 & 0.6 & 0.0 & 0.2 & 13.8 \\
\hline
\end{tabular}


EDS with a TEM was also performed on the 0.5 wt. $\%$ amine GQD-Ce- $\mathrm{ZrO}_{2}$ sample calcined at $400{ }^{\circ} \mathrm{C}$ to possibly detect the presence of GQDs at a lower annealing temperature. Figure 17 shows the presence of Ce-based crystalline particles along with amorphous Zr-based particles. The EDS analysis showed individual crystalline $\mathrm{CeO}_{2}$ particles among an amorphous $\mathrm{ZrO}_{2}$ matrix. The crystallinity of the $\mathrm{CeO}_{2}$ was not detected in either DSC or XRD analysis. DSC did not exhibit an exothermic reaction below $400{ }^{\circ} \mathrm{C}$ nor did XRD show crystalline peaks within samples annealed at $400{ }^{\circ} \mathrm{C}$. More TEM investigations are needed to fully characterize the structures of GQD-Ce$\mathrm{ZrO} 2$ nanocomposites and reveal the phase changes with annealing temperature.
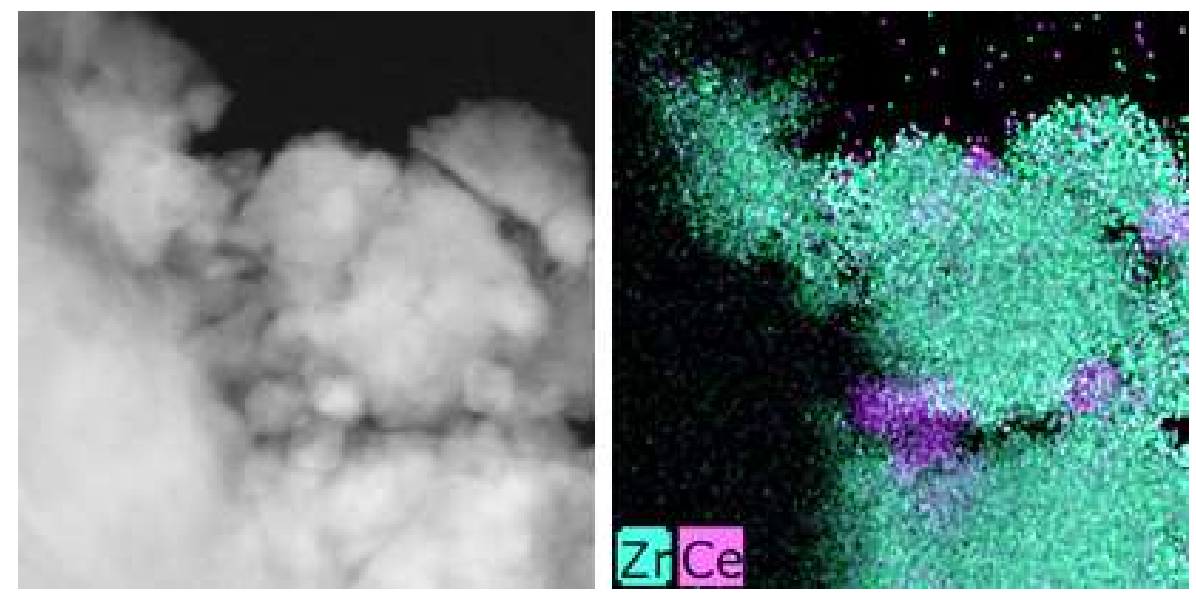

Figure 17. HAADF TEM and EDS mapping images of separate Ce-based agglomerated particles for 0.5 wt. $\%$ amine GQD-Ce- $\mathrm{ZrO}_{2}$ sample calcined at $400{ }^{\circ} \mathrm{C}$.

\subsection{Morphology and Structural Analysis}

The particle morphology of samples (a) $\mathrm{ZrO}_{2}$, (b) $\mathrm{Ce}-\mathrm{ZrO}_{2}$, (c) 0.5 wt. \% amine GQD-Ce- $\mathrm{ZrO}_{2}$, and (d) 0.5 wt. \% carboxyl GQD-Ce-ZrO $\mathrm{rO}_{2}$ are illustrated in the SEM micrographs of Figure 18. Samples containing $\mathrm{CeO}_{2}$ appear to have larger extent of 
particle agglomeration than plain $\mathrm{ZrO}_{2}$, whereas samples with GQDs do not appear to have any observable effects on the morphology. Larger agglomeration may contribute to the larger weight loss in the first TGA step, resulting from a larger release of physically retained water. The average particle size for all samples ranged between of 20-35 nm.

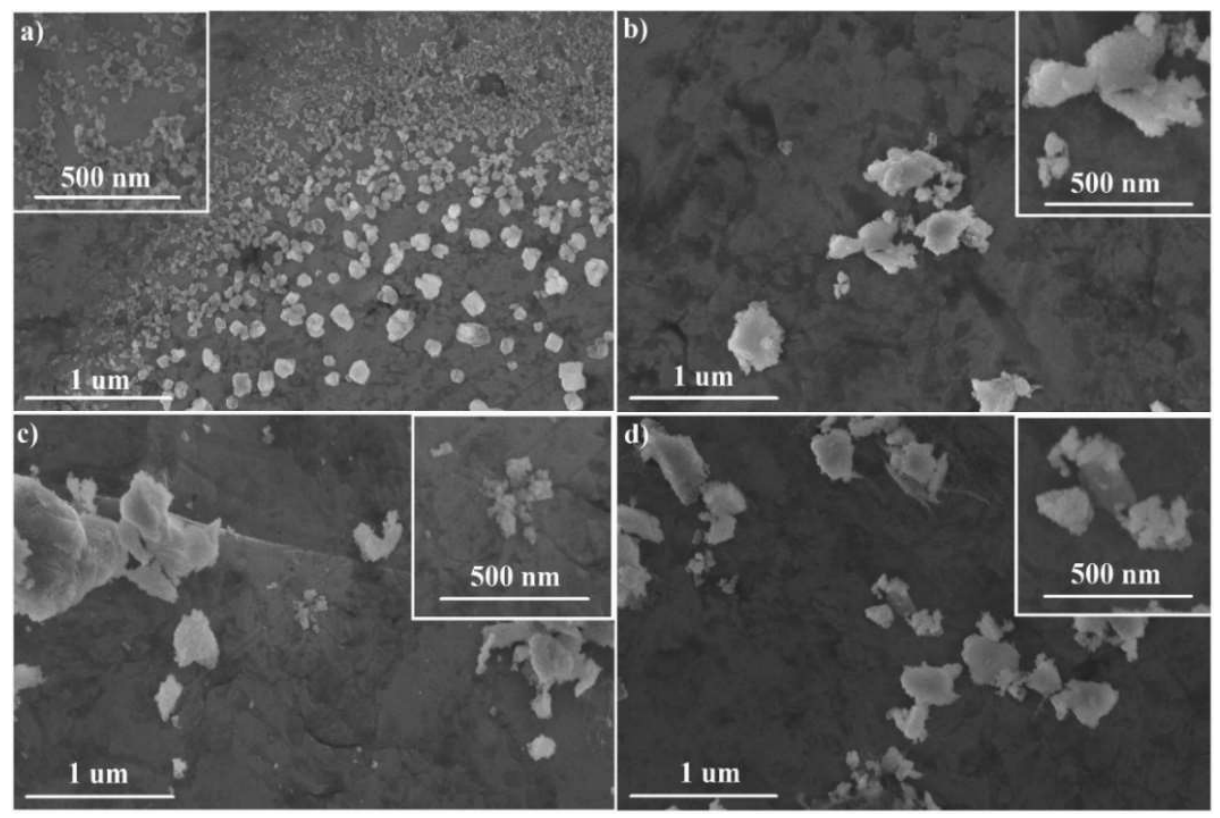

Figure 18. High Resolution SEM (HRSEM) micrographs showing particle morphology of (a) $\mathrm{ZrO}_{2}$, (b) $\mathrm{CeZrO}_{2}$, and $\mathrm{CeZrO}_{2}$ with (c) 0.5 wt.\% amine GQDs and (d) 0.5 wt.\% carboxyl GQDs.

TEM micrographs of (a) $\mathrm{ZrO}_{2}$, (b) Ce- $\mathrm{ZrO}_{2}$, (c) 0.1 wt. \% amine GQD-Ce- $\mathrm{ZrO}_{2}$, and (d) 0.5 wt. $\%$ amine GQD-Ce- $\mathrm{ZrO}_{2}$ are shown in Figure 19. Lattice measurements from the electron diffraction patterns, inserts in each image, are in approximate agreement with XRD lattice parameter measurements. It was extremely difficult to tell but lattice and particle measurements suggested GQDs were observed in some samples. Figure 20 suggests the presence of GQDs for the 0.5 wt. $\%$ amine GQD-Ce- $\mathrm{ZrO}_{2}$ sample (a) unannealed and (b) annealed at $700{ }^{\circ} \mathrm{C}$. The lattice parameter measurements of $0.319 \mathrm{~nm}$ 
and $0.304 \mathrm{~nm}$ are close to the theoretical $0.33 \mathrm{~nm}$ GQD basal plane. The original size of the GQDs were $\sim 10 \mathrm{~nm}$ or smaller and the particles in Figure 20 are also about $10 \mathrm{~nm}$ or less. Further study and reduction of agglomeration are needed to understand the functional attachment of the GQDs to the $\mathrm{ZrO}_{2}$-based matrix.
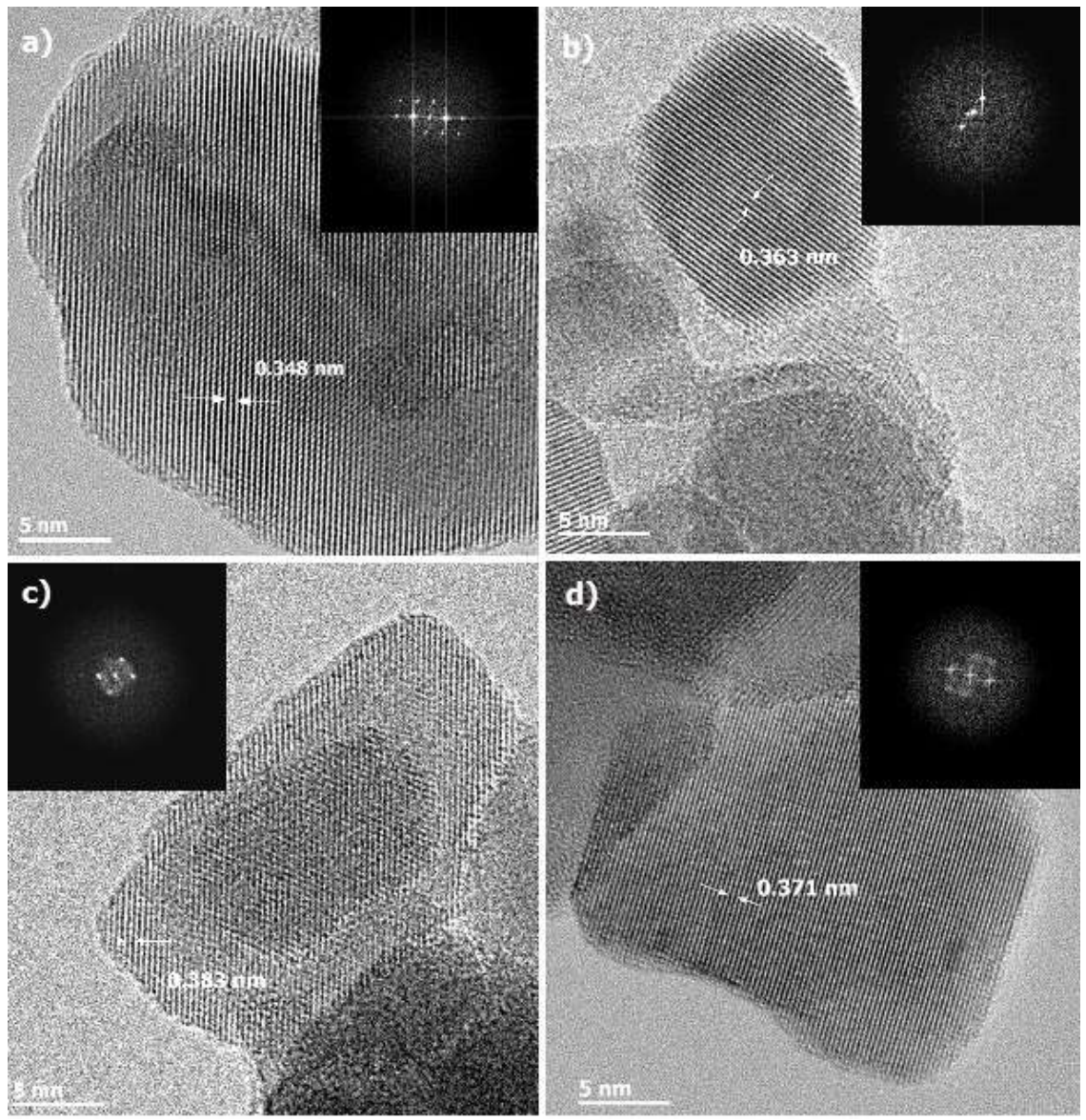

Figure 19. HRTEM micrographs showing diffraction patterns and lattice measurements for (a) $\mathrm{ZrO}_{2}$, (b) $\mathrm{Ce}-\mathrm{ZrO}_{2}$, (c) 0.1 wt. \% amine GQD-Ce- $\mathrm{ZrO}_{2}$ (d) 0.5 wt.\% amine GQD$\mathrm{Ce}-\mathrm{ZrO}_{2}$. 


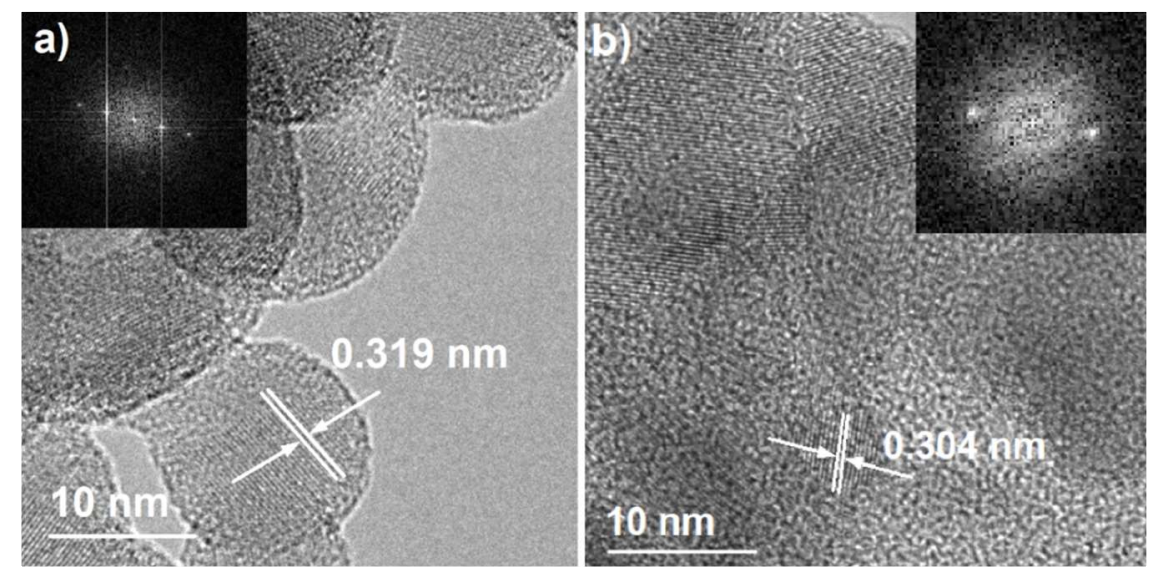

Figure 20. HRTEM micrographs of the (a) 0.5 wt. $\%$ amine GQD-Ce- $\mathrm{ZrO}_{2}$ sample unannealed and of the (b) $0.5 \mathrm{wt} . \%$ amine GQD-Ce- $\mathrm{ZrO}_{2}$ annealed at $700{ }^{\circ} \mathrm{C}$. 


\section{CHAPTER SIX}

\section{CONCLUSION}

In this study, previous $\mathrm{NaBH}_{4}$ precipitated $\mathrm{Ce}-\mathrm{ZrO}_{2}$ was characterized for effects amine and carboxyl GQDs may have on the phase and morphology of Ce-ZrO $\mathrm{rO}_{2}$ nanoparticles. DSC and TGA analysis showed the evolution of $\mathrm{Zr}(\mathrm{OH})_{4}$ to crystalline $\mathrm{ZrO}_{2}$ when heating past $700{ }^{\circ} \mathrm{C}$ through dehydration, release of $\mathrm{OH}^{-}$groups, and crystallization. XRD analysis confirmed the evolution of amorphous to tetragonal phase transformation for resulted $\mathrm{ZrO}_{2}$-based nanoparticles. The presence of $\mathrm{CeO}_{2}$ reduced the amorphous-to-tetragonal transformation temperature by $\sim 40^{\circ} \mathrm{C}$ and reduced the average crystallite size from approximately $19 \mathrm{~nm}$ for $\mathrm{ZrO}_{2}$ to approximately $15 \mathrm{~nm}$ for Ce- $\mathrm{ZrO}_{2}$. There was no discernible effect GQDs had on the crystallinity of the $\mathrm{Ce}-\mathrm{ZrO}_{2}$ structure. XPS compositional analysis revealed 13-14 at. $\% \mathrm{CeO}_{2}$ in the $\mathrm{ZrO}_{2}$ matrix, despite the targeted 16 at. $\%$.

More TEM work is needed to conclude the presence of the GQDs in the $\mathrm{ZrO}_{2}$ systems and the effects they may have on the $\mathrm{Ce}-\mathrm{ZrO}_{2}$ structure. Future studies should focus on sintering of the GQD-Ce- $\mathrm{ZrO}_{2}$ system and characterization of the sintered nanocomposite. The GQDs may survive the sintering process or might produce nanopores. These structures, in turn, could improve toughness of $\mathrm{ZrO}_{2}$ by enhancing transformation toughening or microcrack formation at the crack tip [53]. 


\section{REFERENCES}

[1] G.Y. Guo and Y.L. Chen, "Preparation and characterization of a novel zirconia precursor," Ceram. Int., 30, 469-475 (2004).

[2] K. Shanmugam and R. Sahadevan, "Bioceramics-An introductory overview," Fundam. Biomater. Ceram., 1-46 (2018).

[3] J.L. Gole, S.M. Prokes, J.D. Stout, O.J. Glembocki, and R. Yang, "Unique properties of selectively formed zirconia nanostructures," Adv. Mater., 18, 664667 (2006).

[4] S. Kumar, S. Bhunia, and A.K. Ojha, "Effect of calcination temperature on phase transformation, structural and optical properties of sol-gel derived $\mathrm{ZrO} 2$ nanostructures," Phys. E Low-Dimensional Syst. Nanostructures, 66, 74-80 (2015).

[5] M. Borik, V. Bublik, A. Kulebyakin, E. Lomonova, F. Milovich, V. Myzina, V. Osiko, and N. Tabachkova, "Phase composition, structure and mechanical properties of PSZ (partially stabilized zirconia) crystals as a function of stabilizing impurity content," J. Alloys Compd., 586, S231-S235 (2014).

[6] O. Gorban, S. Synyakina, G. Volkova, S. Gorban, T. Konstantiova, and S. Lyubchik, "Formation of metastable tetragonal zirconia nanoparticles: Competitive influence of the dopants and surface state," J. Solid State Chem., 232, 249-255 (2015).

[7] R.C. Garvie, "The occurrence of metastable tetragonal zirconia as a crystallite size effect," J. Phys. Chem., 69, 1238-1243 (1965).

[8] E. Djurado, P. Bouvier, and G. Lucazeau, "Crystallite size effect on the tetragonalmonoclinic transition of undoped nanocrystalline zirconia studied by XRD and Raman spectrometry," J. Solid State Chem., 149, 399-407 (2000).

[9] P. Li and I. Chen, "Effect of dopants on zirconia stabilization-An x-ray absorption study: III, charge-compensating dopants," J. Am. Ceram. Soc., 77, 1289-1295 (1994).

[10] D.N. Wang and K.M. Liang, "The effect of carbon on the phase stability of zirconia," J. Mater. Sci. Lett., 17, 343-344 (1998).

[11] M.A. Blesa, A.J.G. Maroto, S.I. Passaggio, N.E. Figliolia, and G. Rigotti, "Hydrous zirconium dioxide: interfacial properties, the formation of monodisperse spherical particles, and its crystallization at high temperatures," J. Mater. Sci., 20, 4601-4609 (1985). 
[12] M.I. Osendi, J.S. Moya, C.J. Serna, and J. Soria, "Metastability of Tetragonal Zirconia Powders," J. Am. Ceram. Soc., 68, 135-139 (1985).

[13] P. Bouvier, E. Djurado, G. Lucazeau, C. Ritter, and A.J. Dianoux, "Low temperature phase transformation of nanocrystalline tetragonal ZrO2 by neutron and raman scattering studies," Int. J. Inorg. Mater., 3, 647-654 (2001).

[14] H.Q. Cao, X.Q. Qiu, B. Luo, Y. Liang, Y.H. Zhang, R.Q. Tan, M.J. Zhao, and Q.M. Zhu, "Synthesis and room-temperature ultraviolet photoluminescence properties of zirconia nanowires," Adv. Funct. Mater., 14, 243-246 (2004).

[15] R. Pazhani, H. Padma Kumar, A. Varghese, A. Moses Ezhil Raj, S. Solomon, and J.K. Thomas, "Synthesis, vacuum sintering and dielectric characterization of zirconia (t-ZrO 2 ) nanopowder," J. Alloys Compd., 509, 6819-6823 (2011).

[16] J. Livage, K. Doi, and C. Mazieres, "Nature and thermal evolution of amorphous hvdrated zirconium oxide," J. Am. Ceram. Soc., 51, 349-353 (1968).

[17] V. Grover, R. Shukla, and A.K. Tyagi, "Facile synthesis of ZrO2 powders: Control of morphology," Scr. Mater., 57, 699-702 (2007).

[18] B.B. Nayak, S.K. Mohanty, M.Q.B. Takmeel, D. Pradhan, and A. Mondal, "Borohydride synthesis and stabilization of flake-like tetragonal zirconia nanocrystallites," Mater. Lett., 64, 1909-1911 (2010).

[19] N.B. Nayak and B.B. Nayak, "Temperature-mediated phase transformation, pore geometry and pore hysteresis transformation of borohydride derived in-born porous zirconium hydroxide nanopowders," Sci. Rep., 6, 26404 (2016).

[20] N.B. Nayak and B.B. Nayak, "Aqueous sodium borohydride induced thermally stable porous zirconium oxide for quick removal of lead ions," Sci. Rep., 6, 1-12 (2016).

[21] Z. Du, X.M. Zeng, Q. Liu, A. Lai, S. Amini, A. Miserez, C.A. Schuh, and C.L. Gan, "Size effects and shape memory properties in $\mathrm{ZrO} 2$ ceramic micro- and nanopillars," Scr. Mater., 101, 40-43 (2015).

[22] M. Yashima, "Crystal structures of the tetragonal ceria-zirconia solid solutions CexZr1-xO2 through first principles calculations $(0 \leq x \leq 1)$," J. Phys. Chem. C, 113, 12658-12662 (2009).

[23] A. Savin, M.L. Craus, V. Turchenko, A. Bruma, P.A. Dubos, S. Malo, T. Konstantinova, and V. Burkhovetsky, "Monitoring techniques of cerium stabilized zirconia for medical prosthesis," Appl. Sci., 5, 1665-1682 (2015). 
[24] Z.W. Quan, L.S. Wang, and J. Lin, "Synthesis and characterization of spherical ZrO2:Eu 3+ phosphors by spray pyrolysis process," Mater. Res. Bull., 40, 810820 (2005).

[25] K. Tsukuma and M. Shimada, "Strength, fracture toughness and Vickers hardness of CeO2-stabilized tetragonal ZrO2 polycrystals (Ce-TZP)," J. Mater. Sci., 20, 1178-1184 (1985).

[26] T.W. Coyle, W.S. Coblenz, and B.A. Bender, "Transformation toughening in large-grain-size CeO2-doped ZrO2 polycrystals," J. Am. Ceram. Soc., 71, C-88C-92 (1988).

[27] W. Chen, R. Ran, D. Weng, X. Wu, J. Zhong, A. Zhu, and S. Han, "A facile ceriazirconia binary oxide used for degradation of 2-chloroethyl ethyl sulfide," J. Mater. Sci., 50, 6268-6276 (2015).

[28] D. Arifin and A.W. Weimer, "Kinetics and mechanism of solar-thermochemical $\mathrm{H} 2$ and $\mathrm{CO}$ production by oxidation of reduced CeO2," Sol. Energy, 160, 178-185 (2018).

[29] P. Granger, S. Troncéa, J.P. Dacquin, M. Trentesaux, and V.I. Parvulescu, "Support-induced effect on the catalytic properties of Pd particles in water denitrification: Impact of surface and structural features of mesoporous ceriazirconia support," Appl. Catal. B Environ., 224, 648-659 (2018).

[30] M.A. Ganzoury, S.E.K. Fateen, S.T. El Sheltawy, A.M. Radwan, and N.K. Allam, "Thermodynamic and efficiency analysis of solar thermochemical water splitting using Ce-Zr mixtures," Sol. Energy, 135, 154-162 (2016).

[31] J. Fan, D. Weng, X. Wu, X. Wu, and R. Ran, "Modification of CeO2-ZrO2 mixed oxides by coprecipitated/impregnated Sr: Effect on the microstructure and oxygen storage capacity," J. Catal., 258, 177-186 (2008).

[32] S. Rani, M. Kumar, S. Sharma, D. Kumar, and S. Tyagi, "Effect of graphene in enhancing the photo catalytic activity of zirconium oxide," Catal. Letters, 144, 301-307 (2014).

[33] A. Gallardo-López, I. Márquez-Abril, A. Morales-Rodríguez, A. Muñoz, and R. Poyato, "Dense graphene nanoplatelet yttria tetragonal zirconia composites: Processing, hardness and electrical conductivity," Ceram. Int., 43, 11743-11752 (2017).

[34] M. Onyszko, K. Urbas, M. Aleksandrzak, and E. Mijowska, "Reduced graphene oxide and inorganic nanoparticles composites - Synthesis and characterization," Polish J. Chem. Technol., 17, 95-103 (2015). 
[35] M. Kaur and K. Pal, "An investigation for hydrogen storage capability of zirconiareduced graphene oxide nanocomposite," Int. J. Hydrogen Energy, 41, 2186121869 (2016).

[36] M. Bacon, S.J. Bradley, and T. Nann, "Graphene quantum dots," Part. Syst. Charact., 31, 415-428 (2014).

[37] Y. Wang and A. Hu, "Carbon quantum dots: synthesis, properties and applications," J. Mater. Chem. C, 2, 6921-6939 (2014).

[38] K.L. Schroeder, R. V. Goreham, and T. Nann, "Graphene quantum dots for theranostics and bioimaging," Pharm. Res., 33, 2337-2357 (2016).

[39] G. Wang, A. Xu, P. He, Q. Guo, Z. Liu, Z. Wang, J. Li, X. Hu, Z. Wang, D. Chen, Y. Wang, S. Yang, and G. Ding, "Green preparation of lattice phosphorus doped graphene quantum dots with tunable emission wavelength for bio-imaging," Mater. Lett., 242, 156-159 (2019).

[40] F. Salehnia, F. Faridbod, A.S. Dezfuli, M.R. Ganjali, and P. Norouzi, "Cerium(III) ion sensing based on graphene quantum dots fluorescent turn-off," J. Fluoresc., 27, 331-338 (2017).

[41] A. Kelarakis, "Graphene quantum dots: In the crossroad of graphene, quantum dots and carbogenic nanoparticles," Curr. Opin. Colloid Interface Sci., 20, 354$361(2015)$.

[42] P. Luo, X. Guan, Y. Yu, and X. Li, "New insight into electrooxidation of graphene into graphene quantum dots," Chem. Phys. Lett., 690, 129-132 (2017).

[43] L.M. Long, N.N. Dinh, and T.Q. Trung, "Synthesis and characterization of polymeric graphene quantum dots based nanocomposites for humidity sensing," J. Nanomater., 2016, 1-6 (2016).

[44] S. Bak, D. Kim, and H. Lee, "Graphene quantum dots and their possible energy applications: A review," Curr. Appl. Phys., 16, 1192-1201 (2016).

[45] N. Gobi, D. Vijayakumar, O. Keles, and F. Erogbogbo, "Infusion of graphene quantum dots to create stronger, tougher, and brighter polymer composites," ACS Omega, 2, 4356-4362 (2017).

[46] D. Arthisree and G.M. Joshi, "Study of polymer graphene quantum dot nanocomposites," J. Mater. Sci. Mater. Electron., 28, 10516-10524 (2017).

[47] S. Chinnusamy, R. Kaur, A. Bokare, and F. Erogbogbo, "Incorporation of graphene quantum dots to enhance photocatalytic properties of anatase TiO2," 
MRS Commun., 8, 137-144 (2018).

[48] O. Ruff and F. Ebert, "Refractory ceramics: I. The forms of zirconium dioxide," Anorg. Chem., 180, (1929).

[49] H.R. Chen, J.L. Shi, T. dan Chen, J.N. Yan, and D.S. Yan, "Preparation and characteristics of the ordered porous zirconia containing cerium," Mater. Lett., 54, 200-204 (2002).

[50] K. Aribi, Z. Soltani, M. Ghelamallah, and P. Granger, "Structure, morphology and reducibility of ceria-doped zirconia," J. Mol. Struct., 1156, 369-376 (2018).

[51] N. Guillén-Hurtado, A. Bueno-López, and A. García-García, "Surface and structural characterisation of coprecipitated Cex $\mathrm{Zr} 1-x \mathrm{O} 2(0 \geq x \geq 1)$ mixed oxides," J. Mater. Sci., 47, 3204-3213 (2012).

[52] H.P. Dasari, K. Ahn, S.Y. Park, H. Il Ji, K.J. Yoon, B.K. Kim, H.J. Je, H.W. Lee, and J.H. Lee, "Hydrogen production from water-splitting reaction based on REdoped ceria-zirconia solid-solutions," Int. J. Hydrogen Energy, 38, 6097-6103 (2013).

[53] Q. Jiang, C. Cao, T. Lin, S. Wu, and X. Li, "Strong and tough glass with selfdispersed nanoparticles via solidification," Adv. Mater., 31, 1-5 (2019). 